To appear in Atmosphere-Ocean

Vol. 00, No. 00, Month 20XX, 1-30

\title{
Influence of the model horizontal resolution on atmospheric conditions leading to freezing rain in regional climate simulations
}

\author{
Médéric St-Pierre $^{1 *}$, Julie M. Thériault ${ }^{1} \&$ Dominique Paquin ${ }^{2}$ \\ ${ }^{1}$ Department of Earth and Atmospheric Sciences, Université du Québec à Montréal, Montréal, Québec \\ ${ }^{2}$ Consortium Ouranos, Montréal, Québec
}

(v2.0 released October 2018)

Freezing rain occurs in complex atmospheric conditions when the temperature is close to $0^{\circ} \mathrm{C}$. To better understand how its occurrence will change in the future, there is a need to assess how well regional climate models can reproduce those conditions. The goal of the present study is to investigate the influence of the horizontal resolution on the simulation of freezing rain using the fifth generation of the Canadian Regional Climate Model (CRCM5). Three CRCM5 simulations driven by ERA-Interim reanalysis over Eastern North America at $0.11^{\circ}, 0.22^{\circ}$ and $0.44^{\circ}$ were conducted over a period of 36 years (1979 to 2014). Freezing rain is diagnosed using an in-line diagnostic method for precipitation partitioning. A climatology study of annual and seasonal accumulated freezing rain was conducted. In addition, the ability of the three simulations to reproduce individual freezing rain events was evaluated. Our analyses include frequency and partitioning of different precipitation types and comparisons with observations. All simulations sufficiently reproduced the climatology of freezing rain and show similar large-scale patterns. The number of freezing rain events tend to be overestimated at higher resolution and underestimated at lower resolution. Despite the overestimation, detailed maxima associated with freezing rain are well defined and located at higher resolution, notably in regions located in the St. Lawrence River Valley. Overall, this study is in agreement with other added value studies generally showing a mix of improvements and deteriorations of precipitation fields by the higher resolution simulations.

${ }^{*}$ Corresponding author's email: stpierre.mederic@gmail.com 
KEYWORDS: Freezing rain, regional climate models, spatial resolution, climatology

\section{Introduction}

Freezing rain is one of the most catastrophic hazards occurring during the cold season in North America (Dore, 2003). Ice accumulation can damage the power network, which causes power interruptions. Trees are vulnerable during these events due to the weight of the ice load that cover the branches. The January 1998 Ice Storm caused considerable damage in both southeastern Canada and the northeastern United States, where more than $100 \mathrm{~mm}$ of ice accumulated on the ground (Milton \& Bourque, 1999). Around 400000 residents were without power for two weeks after the storm and it took roughly a month to restore all the networks (Lecomte, Pang, \& Russell, 1998). For the December 2013 ice storm in Toronto, insured losses were estimated at $200 \$$ million excluding damages to trees and wires (Armenakis \& Nirupama, 2014).

Freezing rain at the surface can be associated with two types of atmospheric conditions aloft (Stewart et al., 2015), the warm rain process and the cold process. The most common one at mid-latitudes is the cold process, where ice particles fall in an elevated melting layer (Fig. $\left.1, \mathrm{~T}>0^{\circ} \mathrm{C}\right)$. Ice particles that melt completely or partially before falling in a refreezing layer $\left(\mathrm{T}<0^{\circ} \mathrm{C}\right)$ near the surface will form freezing rain or ice pellets, respectively. Completely melted particles will only refreeze if an activating ice nuclei initiates the freezing of the supercooled drop, which generally occurs at colder temperatures $\left(\mathrm{T}<-15^{\circ} \mathrm{C}\right.$, e.g.: Meyers et al., 1992). If the particle melts partially, the remaining ice within the particle will initiate the freezing to form ice pellets (Thériault et al., 2006). On the other hand, completely melted particles will freeze upon impact with a subfreezing surface to produce freezing rain. In contrast, the warm-rain process involves only liquid particles. Supercooled rain drops are formed through collision/coalescence processes (Kajikawa et al., 1988) in warm clouds $\left(\mathrm{T} \sim-15^{\circ} \mathrm{C}\right)$ and freezes upon impact on the subfreezing surface. These processes are common in the Arctic region (Roberts and Stewart, 2008; Kochtubajda, Mooney, \& Stewart, 2017) and on the ocean shore, e.g., near St. John's 


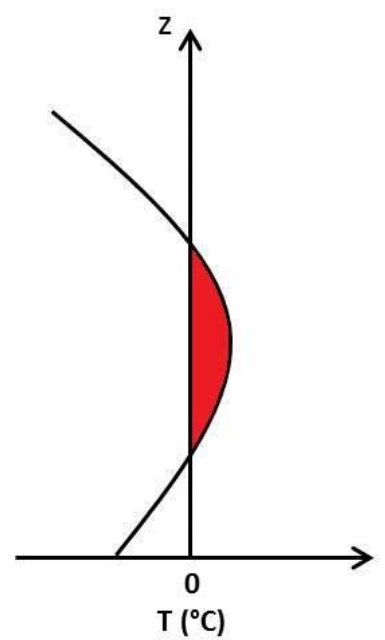

Fig. 1 Typical environmental temperature profile associated with freezing rain. Red area is associated with the melting layer aloft $\left(\mathrm{T}>0^{\circ} \mathrm{C}\right)$. Adapted from Bresson et al. (2017).

Newfoundland (Strapp et al., 1996). Note that freezing drizzle refers to small supercool drops falling very slowly, which will also freeze upon impact with a subfreezing surface (American Meteorological Society, 2018).

Although observed at many locations around the World, most freezing rain occurrences are observed over North America (Groisman et al., 2016). In particular, a maximum in freezing rain is observed over the St. Lawrence River Valley and the Atlantic region with occurrence of $>30$ $\mathrm{h} \mathrm{y}^{-1}$ (Cortinas Jr, Bernstein, Robbins, \& Strapp, 2004; Kotchubajda et al., 2017). It can also be produced in deep topographic valleys where cold air is trapped; e.g., in British Columbia, Canada or in the eastern United States. Freezing rain also occurs in Europe (Carrière, Lainard, Le Bot, \& Robart, 2000) and Northern Eurasia (Groisman et al., 2016) with some areas regularly undergoing $>8 \mathrm{~d} \mathrm{y}^{-1}$ with freezing rain. Such a worldwide occurring, high impact phenomenon should be well reproduced by models to allow for mitigation of the associated risks.

Lambert and Hansen (2011) and Cheng, Auld, Li, Klaassen, and Li (2007) demonstrated that General Circulation Models (GCMs) and statistical methods can reproduce the large-scale patterns of the freezing rain climatology over North America well. The temporal and spatial resolutions, however, are too coarse to identify specific freezing rain events. The use of regional 
climate models (RCMs) with finer resolution has been proposed as an alternative to GCMs for the simulation of freezing rain. The feasibility of the fifth generation of the Canadian Regional Climate Model (CRCM5) using Bourgouin (2000) in-line diagnostic method to produce atmospheric conditions leading to freezing rain using a $0.11^{\circ}$ horizontal resolution has recently been shown by Bresson, Laprise, Paquin, Thériault, and de Elía (2017). Furthermore, Matte et al. (2018) diagnosed the type of precipitation using the same model resolution but with 5 different off-line precipitation-typing algorithms. They show that the various methods lead to different precipitation type distributions at the surface. The potential added value of using ConvectionPermitting Climate Models (CPCMs) is also currently being investigated. For example, some climate research groups have started to conduct simulations, including North America, using horizontal resolutions $\leq 4 \mathrm{~km}$ (Liu et al., 2017) for 10 to 20 years. With this level of detail, the convection is resolved and microphysical processes of clouds and precipitations are parameterized. But, these CPCMs are currently still too costly to be used as operational climate models. To the best of our knowledge, RCMs do not explicitly resolve freezing precipitations and diagnostic methods are still being used (Benjamin, Brown, \& Smirnova, 2016; Bourgouin, 2000).

Given the importance of a better understanding of how freezing precipitation occurrences will change in the future, it is critical to assess how well RCMs simulate the past atmospheric conditions leading to such precipitation type. Currently, ensembles of regional climate simulations data for users over North America are becoming available through the North American Regional Climate Change Assessment Program (NARCCAP; Mearns et al., 2009) at a resolution of $0.44^{\circ}$, and at resolutions of $0.22^{\circ}$ and $0.44^{\circ}$ through the Coordinated Regional Climate Downscaling Experiment (CORDEX). Regional climate modelling has started to be performed with resolutions of $\leq 4 \mathrm{~km}$ (Liu et al., 2017) and another approach to climate projections, such as the pseudo-global warming (PGW) (Schär, Frei, Lüthi, \& Davies, 1996), is being used to study changes in fine-scale processes in warmer conditions.

The goal of this study is to evaluate the gain of using higher spatial resolution to reproduce the atmospheric conditions leading to freezing rain at the surface. This is conducted with CRCM5 
(Martynov et al., 2013; Šeparović et al., 2013) driven by ERA-Interim (Dee et al., 2011) reanalysis over eastern Canada. Historical simulations from 1979 to 2014 have been done at $0.11^{\circ}, 0.22^{\circ}$ and $0.44^{\circ}$ horizontal resolutions.

The paper is divided as follows. The experimental design including a description of CRCM5, the simulations and observations, the diagnostic methods as well as the methodology is given in section 2. Section 3 assesses the spatial and temporal distribution of freezing rain. Differences among resolutions with respect to short and long duration freezing rain events are discussed in section 4. Specific long duration events have also been studied in section 4. Conclusions are stated in section 5 .

\section{Experimental design}

\section{2.a Model description}

The fifth generation of the Canadian Regional Climate Model (CRCM5; Martynov et al., 2013; Šeparović et al., 2013) developed at the Centre pour l'Étude et la Simulation du Climat à l'Échelle Régionale (ESCER) at the Université du Québec à Montréal (UQAM) in collaboration with Environment and Climate Change Canada (ECCC) has been used. It is based on a limited-area version of the Global Environment Multiscale (GEM) model (Côté et al., 1998), which is used at ECCC for numerical weather prediction. GEM is a grid-point model based on a two-time-level semi-Lagrangian (quasi) fully implicit time discretization scheme. It includes a terrain-following vertical coordinate based on hydrostatic pressure (Laprise, 1992) and the horizontal discretization based on a rotated latitude-longitude, Arakawa C grid (Arakawa \& Lamb, 1977). The nesting technique employed in the CRCM5 is derived from Davies (1976). It includes a 10-point wide halo zone along the lateral boundaries for the semi-Lagrangian interpolation and a 10-point sponge zone for a gradual relaxation of all prognostic atmospheric variables toward the driving data along the lateral boundaries. The parameterizations of the CRCM5 are essentially the same as GEM. It includes deep convection from Kain and Fritsch (1990), 
shallow convection issued from a transient version of Kuo (1965) described in Bélair, Mailhot, Girard, and Vaillancourt (2005), large-scale condensation (Sundqvist, Berge, \& Kristjánsson, 1989), correlated-K solar and terrestrial radiation (Li \& Barker, 2005), subgrid-scale orographic gravity waves drag (McFarlane, 1987), low-level orographic blocking parameterization (Zadra, Roch, Laroche, \& Charron, 2003) modified by Zadra, McTaggart-Cowan, and Roch (2012) and planetary boundary layer parameterization (Benoit, Côté, \& Mailhot, 1989; Delage, 1997; Delage \& Girard, 1992) modified in Zadra et al. (2012), introducing turbulent hysteresis. In addition to these GEM parameterizations, the Canadian land-surface scheme version 3.5 (CLASS: Verseghy, 2009; Verseghy, 1991) and Flake lake model (Mironov et al., 2010) are used.

An in-line surface precipitation diagnostic method (Bourgouin, 2000) is used to partition winter precipitation types such as freezing rain and ice pellets. The criteria diagnosing precipitation have been developed and validated with data from the 1989-1990, 1990-1991 and 1991-1992 cold seasons over North America. It is currently operational in the CRCM5 and used at ECCC for medium term forecasting of precipitation types. This method uses vertical temperature profiles. It compares the area between the $0^{\circ} \mathrm{C}$ isotherm and the temperature in both melting (red area, Fig. 1) and refreezing layers on an aerological diagram. The algorithm discriminates snow, rain, freezing rain and ice pellets by comparing these areas. The method also has some limitations. First, it has been developed with a limited number of 54 vertical temperature profiles. Second, it only solves for freezing rain and ice pellets formed through cold processes. In general, in terms of ice accumulations, the warm rain process events collectively contribute much less than the cold rain process events. Therefore, this is an acceptable approximation.

\section{2.b Simulations}

Three CRCM5 simulations with different horizontal resolutions of $0.11^{\circ}, 0.22^{\circ}$ and $0.44^{\circ}$ are used. Each one has a vertical resolution of 56 levels from the surface to $10 \mathrm{hPa}(\sim 30 \mathrm{~km})$ up in the atmosphere, including 14 levels in the first $3 \mathrm{~km}$. They were performed over northeastern North America with respective free domains exclusive of 40 points sponge, and halo zones are 


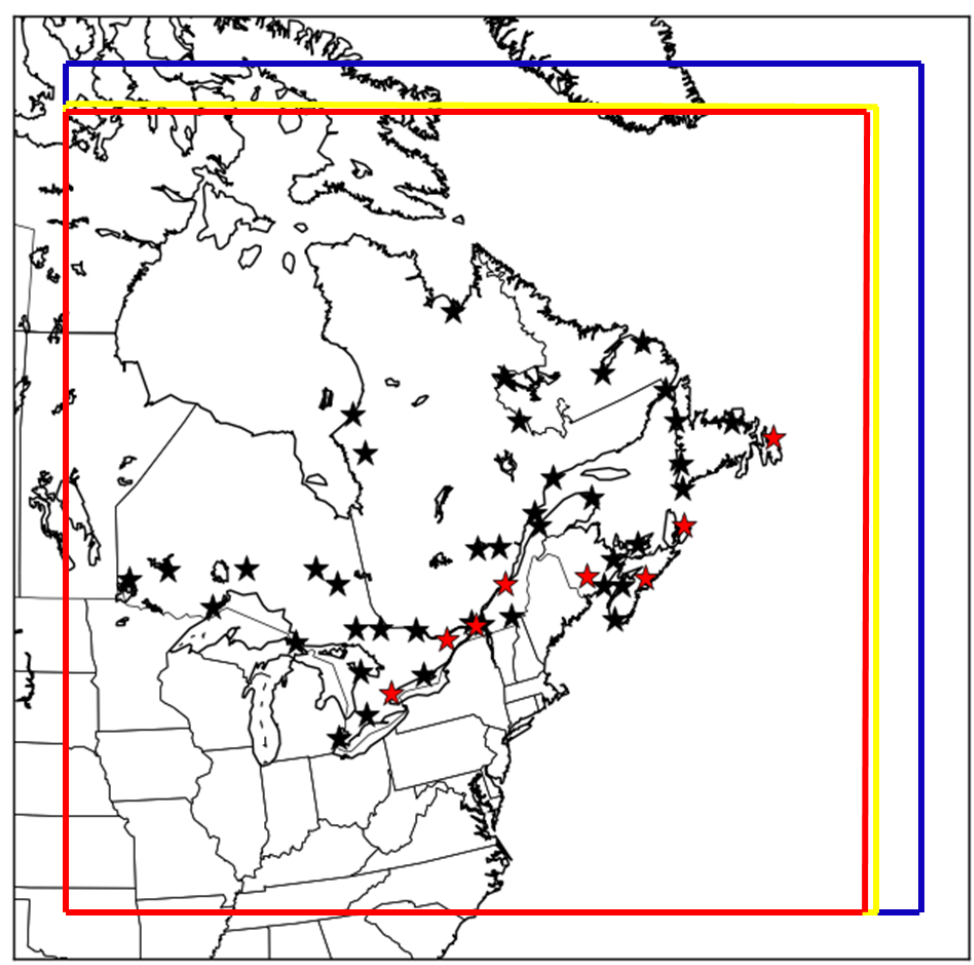

Fig. 2 Domain used for simulations at $0.11^{\circ}, 0.22^{\circ}$ and $0.44^{\circ}$ horizontal resolution. They are indicated in red, blue and yellow, respectively. The stars indicate the locations of the meteorological stations (manual observations, MANOBS) used and the red ones indicate the 8 stations used for the event-based analysis.

composed of $300 \times 300,160 \times 160$ and $76 \times 76$ grid cells. Figure 2 shows the domain for the simulations. The time step is 5,10 and 20 minutes for the $0.11^{\circ}, 0.22^{\circ}$ and $0.44^{\circ}$ simulations, respectively, and all variables are archived every $3 \mathrm{~h}$, but total precipitation is archived every hour. The driving data are the ERA-Interim $0.75^{\circ}$ reanalysis, which is available every $6 \mathrm{~h}$ and daily for ocean data. The simulations covered a 36-year period starting in January 1979 and ending in December 2014, the first year being discarded as spin-up time. The $0.11^{\circ}$ simulation is the same as in Bresson et al. (2017). Finally, no spectral nudging is applied in these simulations.

\section{2.c Definition of freezing rain events}

Surface MANual OBServations (MANOBS) are provided hourly by ECCC for 77 meteorological stations over eastern Canada. The studied stations have been chosen according to the data quality control made in Bresson et al. (2017), which is based on the continuous availability of 
30-year data at a given station. Only the stations where hourly occurrences of freezing rain and ice pellets, wind speed and temperature are available from 1980 to 2010 are used. Therefore, only 48 stations are used for this study (Fig. 2). Note that accumulated freezing rain is not available in the MANOBS, so only the occurrences of precipitation will be studied.

To conduct an event-based analysis, 8 stations indicated in Figure 2 (red stars) were selected. These are stations where high amounts of freezing rain are reported annually $(\geq 30 \mathrm{~h})$ or are associated with major cities in eastern Canada. These selected stations are Toronto and Ottawa (Ontario), Montréal and Québec City (Québec), Halifax and Sydney (Nova Scotia), St. John's (Newfoundland) and Fredericton (New Brunswick). All freezing rain events from 1980 to 2010 for these 8 stations will be identified in both observations and simulations and a more in-depth study will be conducted.

A freezing rain event is defined as follows. The event starts at the first recorded observation or simulation of freezing rain and ends after more than $6 \mathrm{~h}$ without freezing rain. These CRCM5 simulations provide only information on freezing rain on a $3 \mathrm{~h}$ basis. Because the model has a tendency to overproduce very light precipitation at the surface, a threshold of $1 \mathrm{~mm} \mathrm{~d}^{-1}$ of freezing rain has been determined to eliminate negligible amounts. The same threshold value was used in Bresson et al. (2017) and in Lambert and Hansen (2011) with GCMs. For each given period of $3 \mathrm{~h}$ with precipitation greater than this threshold, a $3 \mathrm{~h}$ freezing rain duration is added to the event. Consequently, events duration will always be a multiple of three hours.

To be consistent and avoid artificial overestimation, the observations have been treated similarly. The observations were integrated on a $3 \mathrm{~h}$ period as in Bresson et al. (2017). If at least $1 \mathrm{~h}$ of freezing rain is observed for each period, $3 \mathrm{~h}$ is added to the duration of the event. The closest grid cell to each meteorological station was selected for the 3 simulations and compared with observations. This method is also used in Matte et al. (2018) and Lucas-Picher, Laprise, and Winger (2017).

Freezing rain events were then divided into two categories. Short duration (SD) events will be defined as $\leq 6 \mathrm{~h}$ and therefore, long duration (LD) events will last $>6 \mathrm{~h}$. This definition of the 
freezing rain event is similar to the one in previous studies, such as Ressler, Milrad, Atallah, and Gyakum (2012) and Matte et al. (2018). They consider SD event as $<6$ h. In our definition, we include the $6 \mathrm{~h}$ events in the SD events category because of the lower frequency ( $3 \mathrm{~h})$ outputs. This definition allows preventing a SD event (shorter than $3 \mathrm{~h}$ ) archived over 2 consecutive model outputs to be considered a LD event.

\section{2.d Data analysis}

First, a climatological study was conducted. In particular, the precipitation and surface temperature biases, the seasonal average, the spatial and the temporal distributions of freezing rain were investigated using the median annual hours. Precipitation amounts and surface temperatures were compared to the Climate Research Unit (CRU) database (Harris, Jones, Osborn, \& Lister, 2014).

Second, the difference and similarities among the model resolutions were assessed through two different analyses. The occurrences of freezing rain such as the number of events per year were compared with observations. The ability of the model simulations to reproduce past observed freezing rain events within a given time range was calculated. The method considered only the closest grid cell, in each simulation, associated with a given meteorological station. It is called the 1-point analysis. Using this method, observed events are considered reproduce by the simulations if $3 \mathrm{~h}$ of freezing rain is simulated within a range of $12 \mathrm{~h}$ before and after the observed event.

Third, following the 1-point analysis, a thorough analysis of the atmospheric conditions of all missed freezing rain events was conducted. Three parameters are necessary to diagnose freezing rain, which are the minimum amount of precipitation, the melting layer aloft $\left(\mathrm{T}>0^{\circ} \mathrm{C}\right)$ and the below $0^{\circ} \mathrm{C}$ surface temperature. All 3 parameters are investigated for each output frequency ranging from $12 \mathrm{~h}$ before and after the event following the decision tree showed in Figure 3. The analysis led to 4 possible vertical temperature structures defined in Figure 4 . These are associated with different types of precipitation at the surface. Case 1, 2, 3 and 4 would lead to rain or snow, snow only, ice pellets or rain, and freezing rain or ice pellets, respectively. Since 


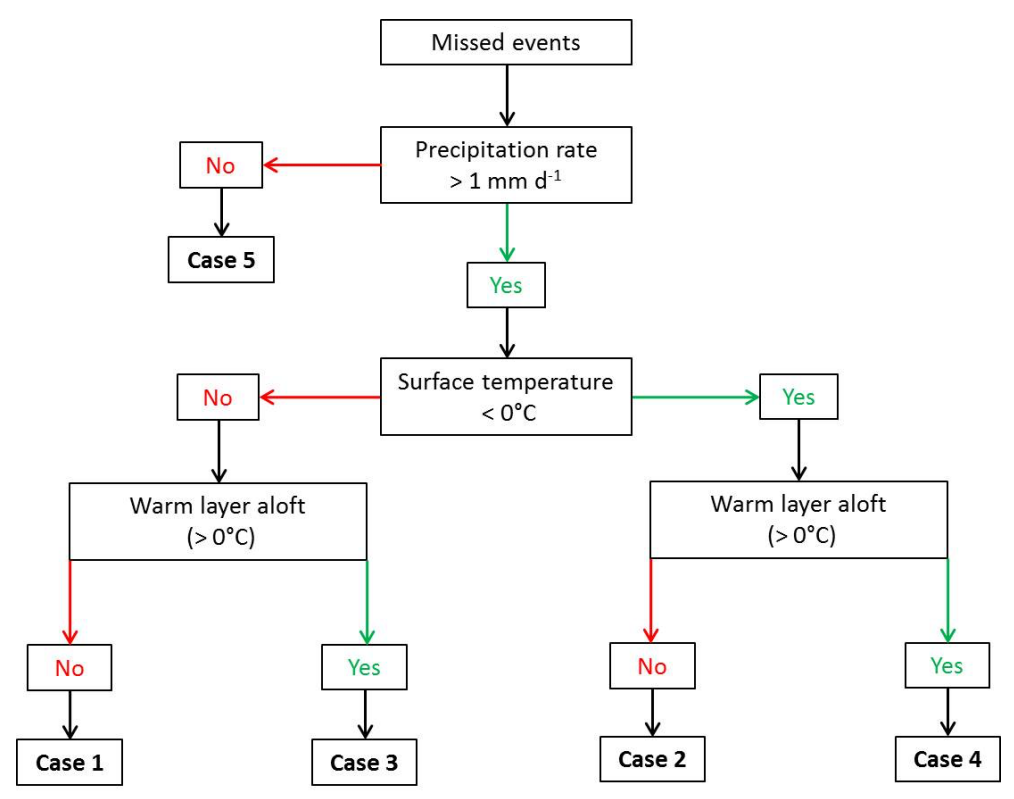

Fig. 3 Schematic diagram showing the method used to diagnose the events that were not reproduced by the simulations. This method has been applied for every output range between $12 \mathrm{~h}$ before and after the missed observed events. This decision tree is based on the assumptions in Bourgouin (2000) so freezing rain can only be diagnose when the surface temperature is $<0^{\circ} \mathrm{C}$.

the cases are analyzed when there is no freezing rain (missed events), case 4 is always associated with ice pellets. Finally, Case 5 occurred when there is no precipitation.

Finally, since the climatology is the summation of all single events occurring annually, specific events, especially the 1998 ice storm, were selected and examined in detail to quantify the ability of the model to reproduce those events. The analysis includes the temporal evolution of precipitation types and temperature at the surface, vertical temperature structure and the spatial distribution.

\section{Climatology}

The ability of the CRCM5 to reproduce the freezing rain climatology over a period of 31 years (1980-2010) was evaluated. The climatology of total precipitation during winter and spring was investigated followed by the spatial and temporal distributions of freezing rain. 
(a) Case 1

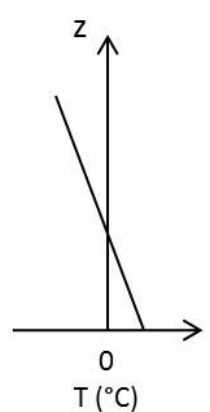

(b) Case 2

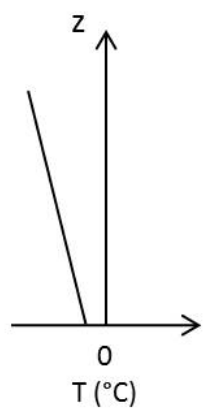

(c) Case 3

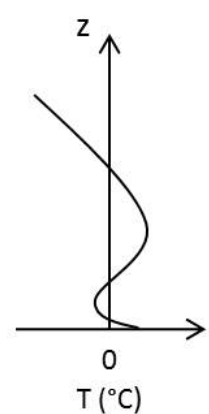

(d) Case 4

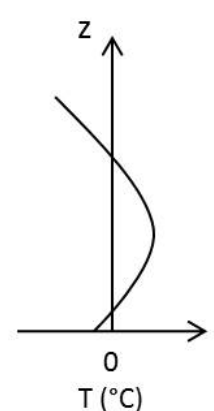

Fig. 4 Vertical temperature profiles leading to the 4 cases identified in Figure 3 . Assuming that there is precipitation at the surface, (a) has no melting layer aloft, but temperatures $>0^{\circ} \mathrm{C}$ at the surface, so snow or rain could reach the surface; (b) is when the vertical temperature structure is all $<0^{\circ} \mathrm{C}$ leading to snow at the surface; (c) has a melting layer aloft a refreezing layer with surface temperatures $>0^{\circ} \mathrm{C}$, which could lead to ice pellets or rain and (d) a melting layer aloft and surface temperatures $<0^{\circ} \mathrm{C}$ leading to freezing rain and ice pellets. In the case, where no freezing rain event is simulated, the precipitation type at the surface is ice pellets.

\section{3.a Simulated precipitation and 2-m temperature}

Precipitation biases with respect to the CRU database, over land, at the three horizontal resolutions during winter (DJF) and spring (MAM), when most of the freezing rain occurs, are shown in Figure 5. The three simulations produced an overall wet bias over the whole domain. The bias is of the order of $0.53,0.47$ and $0.44 \mathrm{~mm} \mathrm{~d}^{-1}$ during MAM and $0.29,0.31$ and 0.30 during DJF for the $0.11^{\circ}, 0.22^{\circ}$ and $0.44^{\circ}$ simulations, respectively. The southern part of the domain shows a dry bias that seems to be related mostly to the boundary effect, with some variation due to the terrain, in particular near the Appalachian Mountains. The largest maxima were near the Great Lakes with values up to $1.50 \mathrm{~mm} \mathrm{~d}^{-1}$. This wet zone was broader with increasing resolution for MAM but similar during DJF. East of the Lake Superior, the three simulations produced the same dry region compared to the observations in winter $\left(-0.10\right.$ to $\left.-1 \mathrm{~mm} \mathrm{~d}^{-1}\right)$. The model may be missing lake effect events from Lake Superior. Similarly, sea effect events from the Labrador Sea may be missed by the model resulting in a dry bias $\left(-0.10\right.$ to $\left.-0.75 \mathrm{~mm} \mathrm{~d}^{-1}\right)$ over the Labrador region. Northeast Québec also have some dry biases $\left(-0.10\right.$ to $\left.-0.50 \mathrm{~mm} \mathrm{~d}^{-1}\right)$. A relatively dry region was also produced by the simulation at $0.11^{\circ}$ in southern Newfoundland 

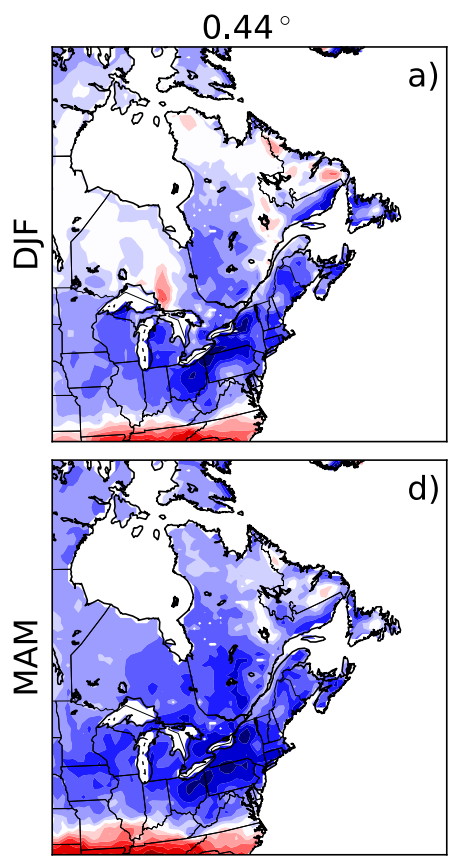
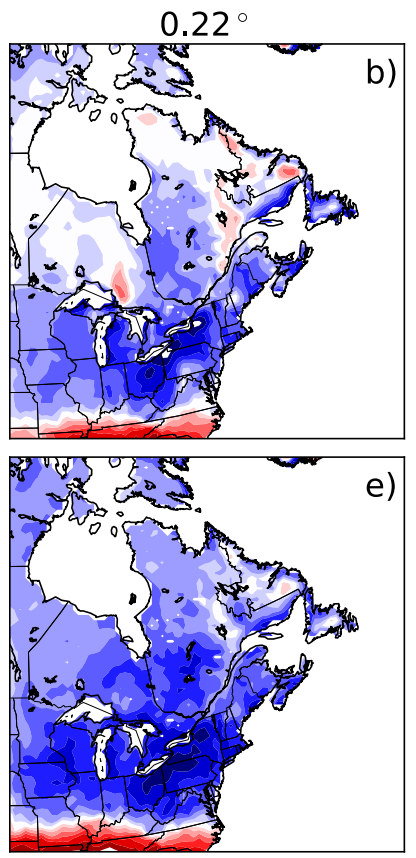
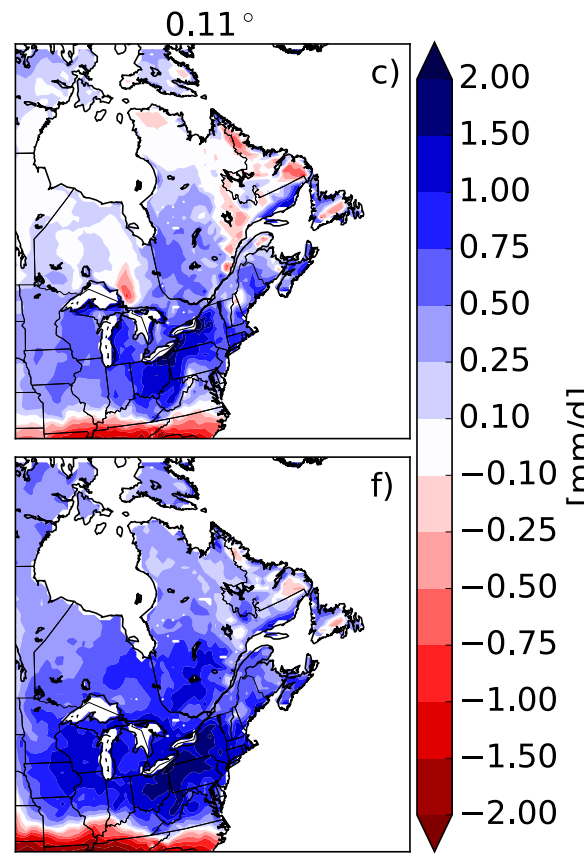

Fig. 5 Precipitation bias with respect to CRU for (a, b, c) winter (DJF) and (d, e, f) spring (MAM) at $0.44^{\circ}, 0.22^{\circ}$ and $0.11^{\circ}$ horizontal resolutions over northeastern North America for the period from 1980 to 2010 .

for both DJF and MAM.

Figure 6 shows the mean surface temperature biases for winter and spring. A relatively warm $\left(0.5\right.$ to $\left.5^{\circ} \mathrm{C}\right)$ bias is covering the south of the domain and the East coast of the United-States during both seasons. This bias is weaker and covers a smaller area during spring. In winter, this bias also affects a major part of Ontario and Québec and it is higher at lower resolution. In spring, a cold bias $\left(-0.5\right.$ to $\left.-5^{\circ} \mathrm{C}\right)$ is displayed over most Ontario and Québec and it is also observed over Newfoundland and Labrador. This cold bias is only observed relatively north during winter. It is stronger and covers a larger area at higher resolution during both seasons. A relatively cold bias $\left(-0.5\right.$ to $\left.-5^{\circ} \mathrm{C}\right)$, with the strength depending on the resolution and season, is also observed south of the Great Lakes and covering up to Missouri and Iowa. A low cold bias is observed in spring on the East Coast going from New Jersey to Massachusetts and a warm bias, stronger at lower resolution, is produced on the Northwest part of the domain over Nunavut. 

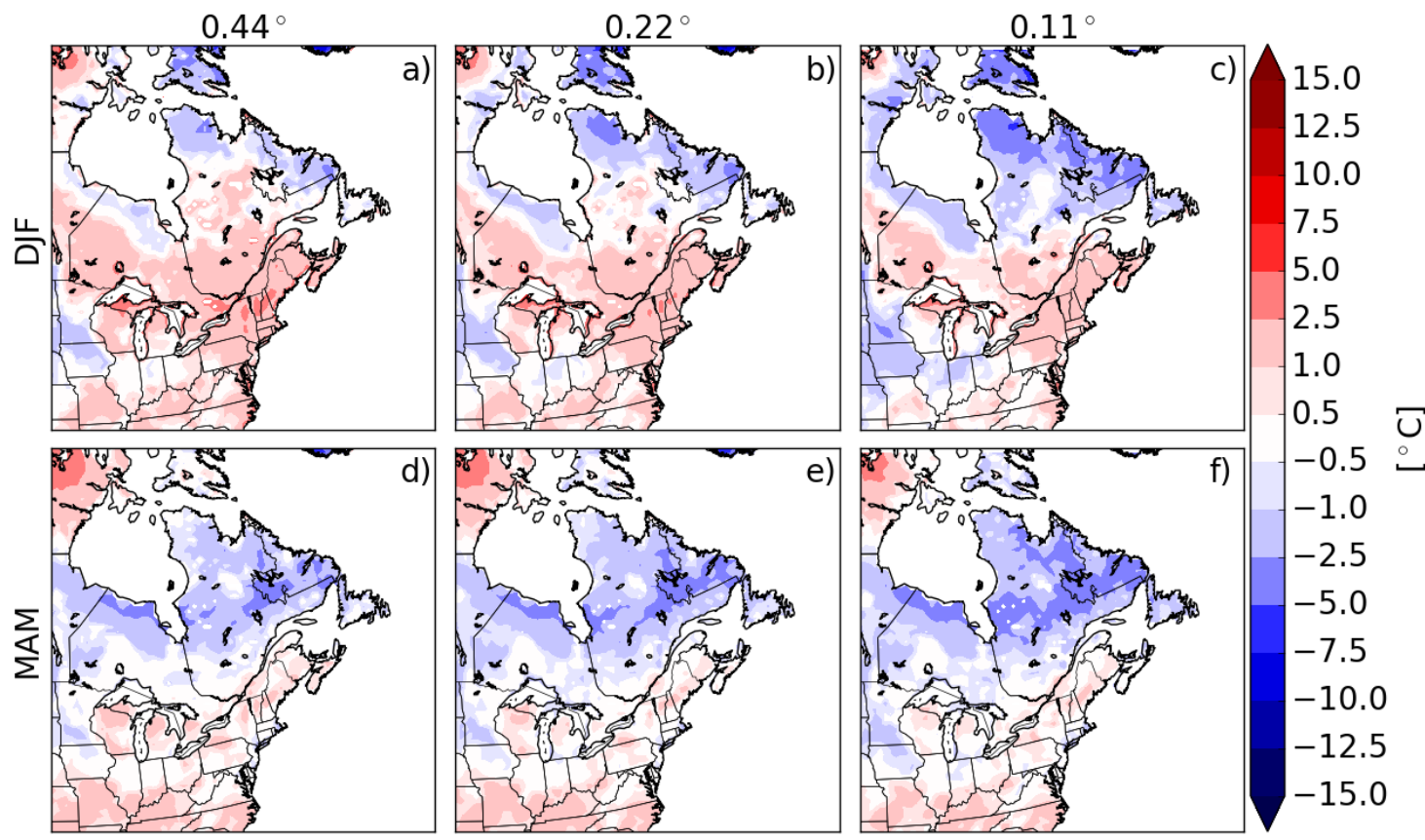

Fig. 6 Mean surface 2-m temperature bias with respect to CRU for (a, b, c) winter (DJF) and (d, e, f) spring (MAM) at $0.44^{\circ}, 0.22^{\circ}$ and $0.11^{\circ}$ horizontal resolutions over northeastern North America for the period from 1980 to 2010.

\section{3.b Annual and seasonal median number of hours}

The median annual hours of freezing rain simulated and observed during the 31-year period from 1980 to 2010 is shown in Figure 7 (a to d). The means, biases, root means square errors (rmse) and least square regression (lsr) are shown in Figure 8 for the 48 stations. Summer (JJA) has been excluded from the scores due to the absence of freezing rain at the stations for this season. As the horizontal resolution increases, local maxima of freezing rain were better defined. For example, a clear local maximum was reproduced along the St. Lawrence River Valley, on the northern shore of Québec, in the center of New Brunswick and on the Atlantic Coast at $0.11^{\circ}$ and $0.22^{\circ}$ resolutions. Nonetheless, comparing the observations to the closest point in each simulation, the general overestimations (bias) reach $33 \%(14.38 \mathrm{~h}), 30 \%(10.57 \mathrm{~h})$ and $8 \%(4.57$ h) for the $0.11^{\circ}, 0.22^{\circ}$ and $0.44^{\circ}$, respectively (Fig 8). The number of hours of freezing rain increased with increasing horizontal resolution, as well as the general overestimation.

The occurrence of freezing rain varied significantly with the seasons (Fig. 7e-t). During winter (DJF), most of the region south of the $50^{\circ}$ latitude was affected by freezing rain. This 
area extended farther north during spring (MAM) and, only along the northern coast of Québec and south of Baffin Island during summer (JJA). During winter, the maxima were located in the St. Lawrence River Valley. These maxima increased with increasing resolution in both covered area and occurrences (from around $35 \mathrm{~h}$ to more than $50 \mathrm{~h}$ ). During fall (SON), the region associated with freezing rain was similar as for spring but with much smaller amounts ( $\sim 40 \%$ less). The ground being warmer in fall than spring may explain the lower occurrences of freezing rain. Spring and winter occurrences of freezing rain were the highest, for all simulations, according to the 48 grid cells in each simulation (Fig. 8). However, the simulations differ from the observations during spring where the biases are $5.31,7.75$ and $8.88 \mathrm{~h}$ for the $0.44^{\circ}, 0.22^{\circ}$ and $0.11^{\circ}$ simulations, respectively, whereas the biases are $-1.12(0.43), 1.44(0.69)$ and $3.38(1.81)$ during winter (fall).

Overall, the annual and seasonal spatial distributions of freezing rain were comparable to the observations at all resolutions. Occurrences during spring are overestimated in each simulation, but for the other seasons, they are closer to the observations. Local maxima were better defined at higher resolution, such as in the St. Lawrence River Valley. On the other hand, the occurrences of freezing rain were higher with increasing resolution compared to the observations, leading to a larger overestimation at higher resolution.

\section{3.c Monthly variation of freezing rain}

The temporal distributions of freezing rain for 8 locations are shown in Figure 9. For the Atlantic locations, 3 of the 4 (Halifax, Fredericton, Sydney and St. John's) stations have a maximum occurrence during March or April, for both simulations and observations, whereas Fredericton had no defined peak. On the other hand, in the St. Lawrence River Valley (Montréal and Québec City), and at Ottawa, the peak of freezing rain was instead observed during December. The simulations agreed with the observations from Québec City, but the $0.11^{\circ}$ and $0.22^{\circ}$ simulations at Montréal and the $0.44^{\circ}$ simulation at Ottawa showed this peak in January. Toronto is the only station where the maximum was simulated in February, with observations showing somewhat 


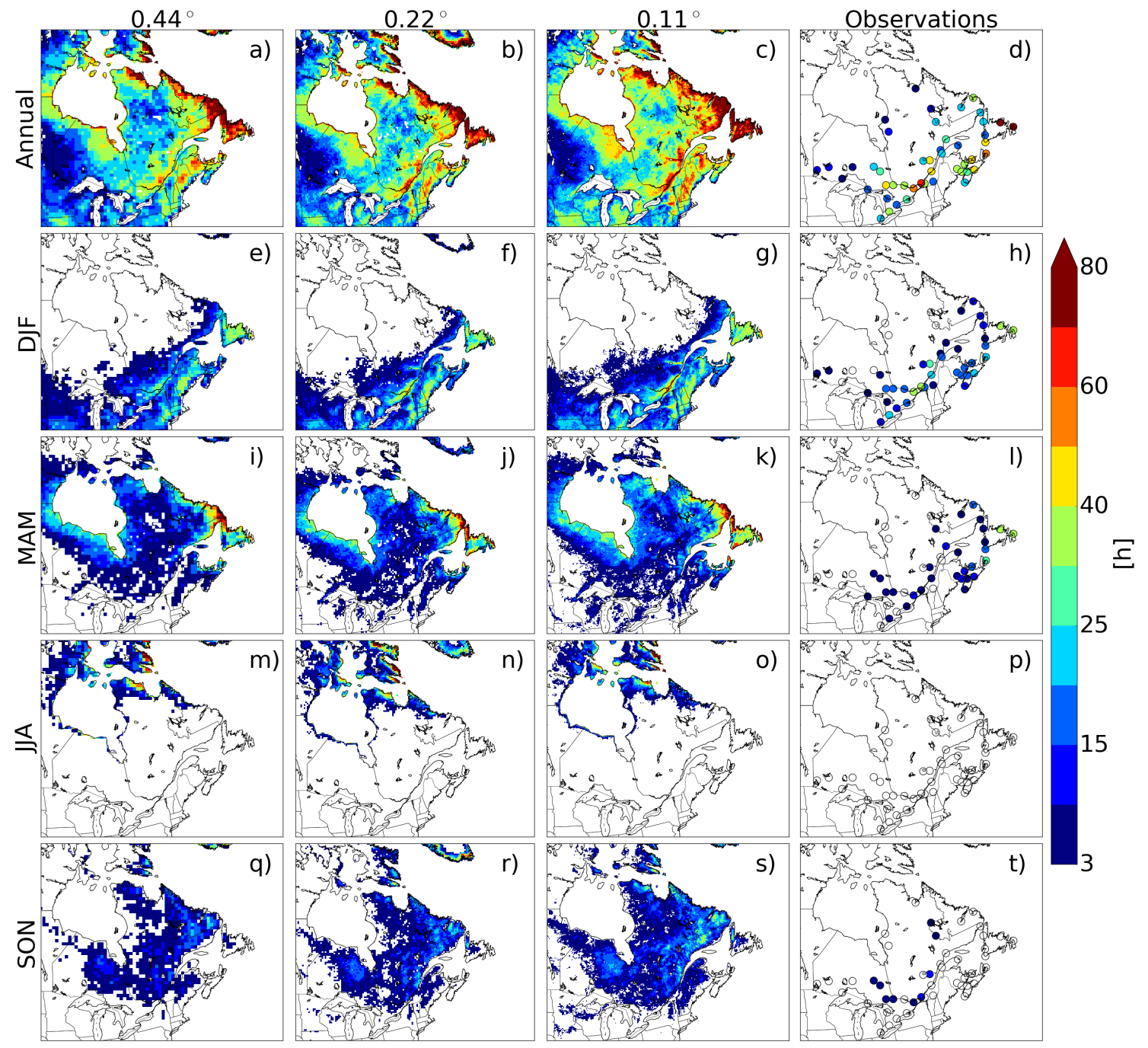

Fig. 7 Annual (a to d) and Seasonal median occurrences of freezing rain [h] during (e to h) winter (DJF), (i to l) spring (MAM), ( $\mathrm{m}$ to p) summer (JJA) and (q to t) autumn (SON) for the CRCM5 simulations (column 1 to 3 ) and the observations (column 4) from 1980 to 2010.

constant values from January to March. As discussed in the previous section, the occurrences of freezing rain increased with increasing resolution, which is supported by Figure 7 . This increase could be explained by the higher resolution being able to resolve narrow freezing rain areas. Finally, the $0.44^{\circ}$ simulation often underestimated freezing rain occurrences compared to the observations.

The simulations reproduced fairly well the monthly cycle of freezing rain. As the resolution increased, the occurrence of freezing rain increases in locations influenced by the topography 

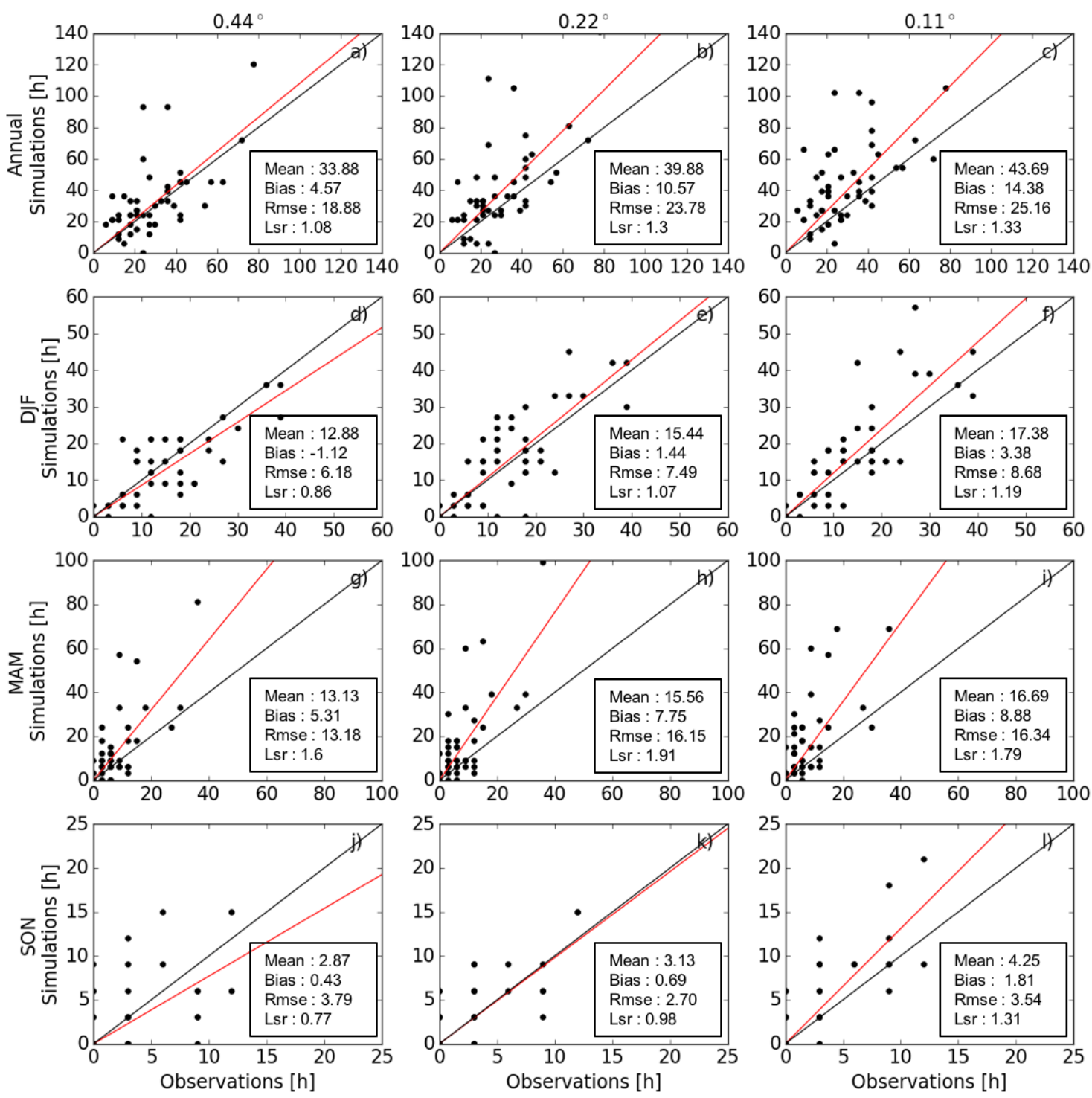

Fig. 8 Comparison between the number of freezing rain hours observed and simulated annually (a to c) and for winter (d to f), spring ( $\mathrm{g}$ to $\mathrm{i}$ ) and autumn (j to k) from 1980 to 2010. The mean, bias, rmse and lsr are shown for each season and simulation. Each black dot is a station. The red line is the slope of the linear regression.

(Montréal and Québec City). A better definition allowed a better simulation of the wind channeling effect in the St. Lawrence River Valley (not shown, as in Cholette, Laprise, and Thériault (2015); Lucas-Picher et al. (2017)). This led to a cold air layer near the surface, which is a favorable condition for freezing rain. A better definition of the topography would lead to a better representation of the wind speed and direction. However, a larger wet bias at higher resolution (Fig. 5) combined with the temperature bias (Fig. 6) could partially explain the overestima- 

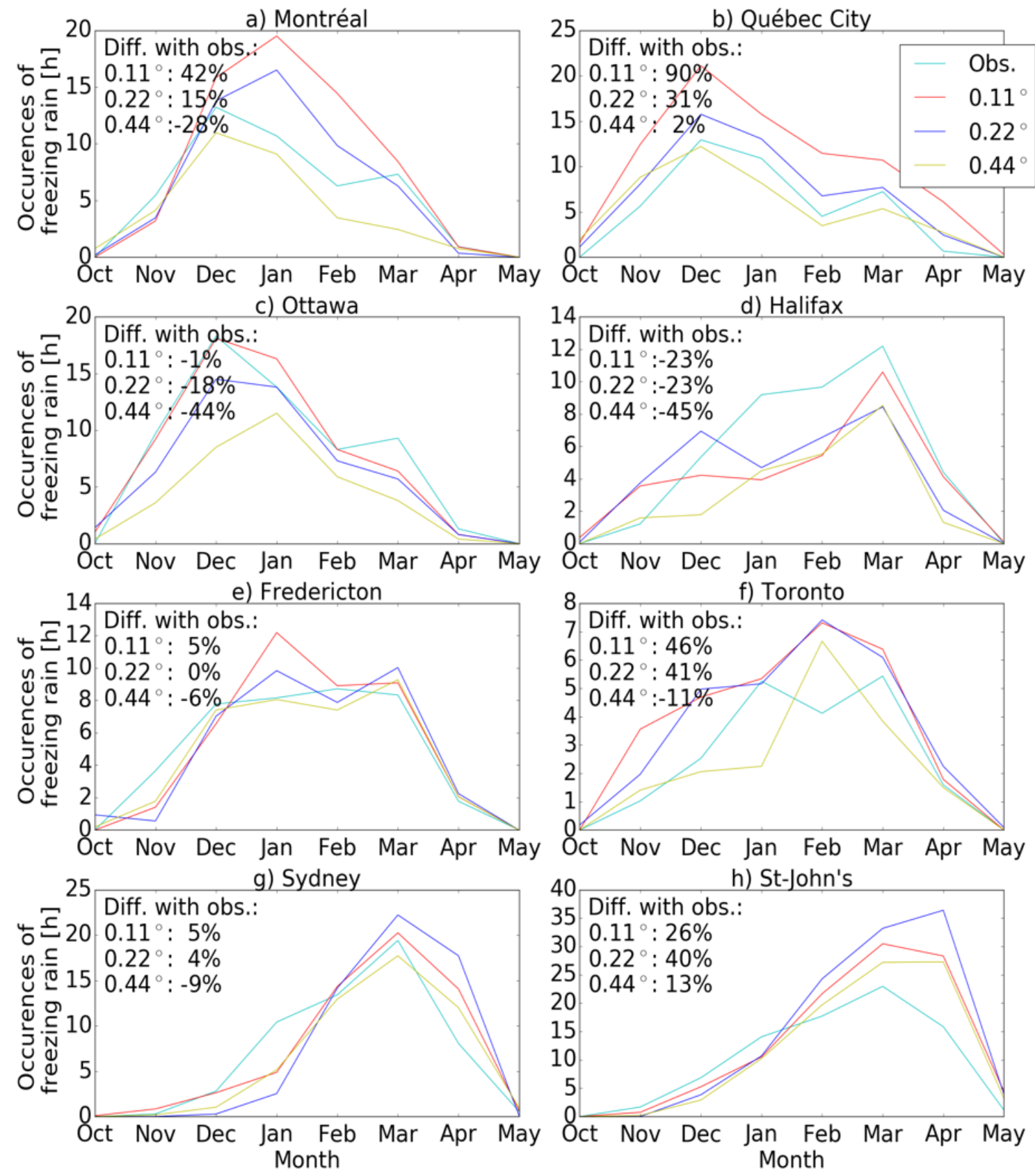

Fig. 9 Temporal distributions of freezing rain simulated with the CRCM5 at $0.11^{\circ}, 0.22^{\circ}$ and $0.44^{\circ}$ horizontal resolutions and observed for 8 locations for the period from 1980 to 2010 . The errors with respect to the observations are indicated in the top left corner. The location of these stations is given in Figure 2.

tion of freezing rain in the St. Lawrence River Valley. This could be due to the mean surface temperature bias during freezing rain (section 4a). 

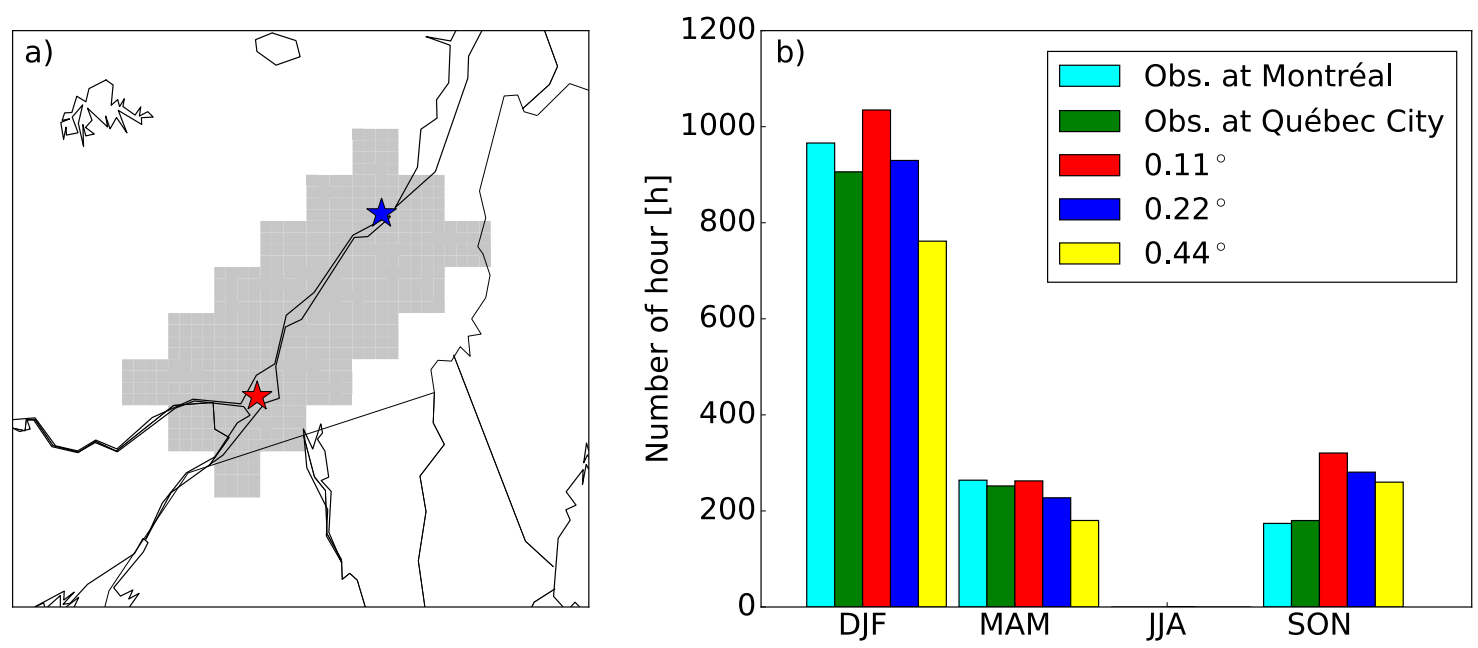

Fig. 10 Seasonal climatology of the St. Lawrence River Valley for the period from 1980 to 2010. (a) The 448, 112 and 28 grid cells selected for the $0.11^{\circ}, 0.22^{\circ}$ and $0.44^{\circ}$ simulations, respectively. The red star is located in Montréal and the blue star is located in Québec City. (b) Averaged number of freezing rain hours per grid cell for the grey zone in (a).

\section{3.d Climatology in the St. Lawrence River Valley}

To evaluate the occurrence of freezing rain in the St. Lawrence River Valley, the average number of hours per grid cell defined in an area covering the valley were compared at all resolutions (Fig. 10). The area, shown in Figure 10a, includes Montréal and Québec City. The selected region is a rectangle composed of 448,112 and 28 grid cells for the $0.11^{\circ}, 0.22^{\circ}$ and $0.44^{\circ}$ simulations, respectively. According to Figure 7 this region is associated with a freezing rain maximum.

As expected, freezing rain was occurring essentially during winter, with $\sim 3$ to 5 times less occurrence in spring and fall (Fig. 10b). The number of hours increased with increasing resolution. The difference between the $0.44^{\circ}$ and the $0.11^{\circ}\left(0.22^{\circ}\right)$ resolutions for the 31-year period are $\sim 300 \mathrm{~h}(180 \mathrm{~h})$ in winter, respectively. During fall, the number of hours could be over-produced due to the model cooling the ground too quickly. Finally, the number of hours at higher resolutions $\left(0.11^{\circ}\right.$ and $\left.0.22^{\circ}\right)$ is more comparable to observations than the coarser one $\left(0.44^{\circ}\right)$, except in the fall. 


\section{Event based comparison}

\section{4.a Number of freezing rain events}

The freezing rain event analysis showed a majority of short duration (SD) events in both simulations and observations (Fig. 11). The number of events decreased with the duration and only a few events lasted more than $30 \mathrm{~h}$ for the 8 stations. According to the observations, SD events are $65 \%$ to $80 \%$ of the total number of events at each station. In particular, the highest resolutions have a clear tendency to overestimate the number of SD events west of the domain (Montréal, Québec City, Ottawa and Toronto).

The number of freezing rain events per year at each station is shown in Figure 12. For the western stations of the domain (Montréal, Québec City, Ottawa and Toronto), the highest resolution simulations generally overestimated freezing rain events. Combining these 4 stations, LD events were overestimated by the $0.11^{\circ}$ and $0.22^{\circ}$ simulations ( $57 \%$ and $35 \%$, respectively). On the other hand, the SD event were overestimated at $0.11^{\circ}(19 \%)$ and underestimated ($12 \%$ ) at $0.22^{\circ}$. The behaviour differs in the Atlantic region (Fredericton, Halifax, St. John's and Sydney). The differences are independent to the model resolution and vary locally. For example, the $0.11^{\circ}$ and $0.22^{\circ}$ simulations underestimate both types of event at all stations, except for the LD at Sydney and St. John's. Highest resolution simulations, $0.11^{\circ}$ and $0.22^{\circ}$, show a negative bias for $\mathrm{SD}(-14 \%$ and $-23 \%)$, but positive for $\mathrm{LD}(6 \%$ and $12 \%)$. In comparison, the $0.44^{\circ}$ simulation underestimated both LD and SD events by $-6 \%$ and $-26 \%$. In general, the $0.11^{\circ}$ and $0.22^{\circ}$ simulations tend to overestimate the number of events for the western stations, but the results were closer to the observations in the Atlantic region. The $0.44^{\circ}$ simulation, however, was different because it underestimated most of the freezing rain events. This analysis was also conducted with the number of hours, which gives similar results (St-Pierre, 2018).

The observed and simulated mean temperatures at which freezing rain occurs during SD and LD events are shown in Figure 13. This analysis helps to understand the simulated environmental conditions leading to differences in the occurrences of freezing rain events. We already 

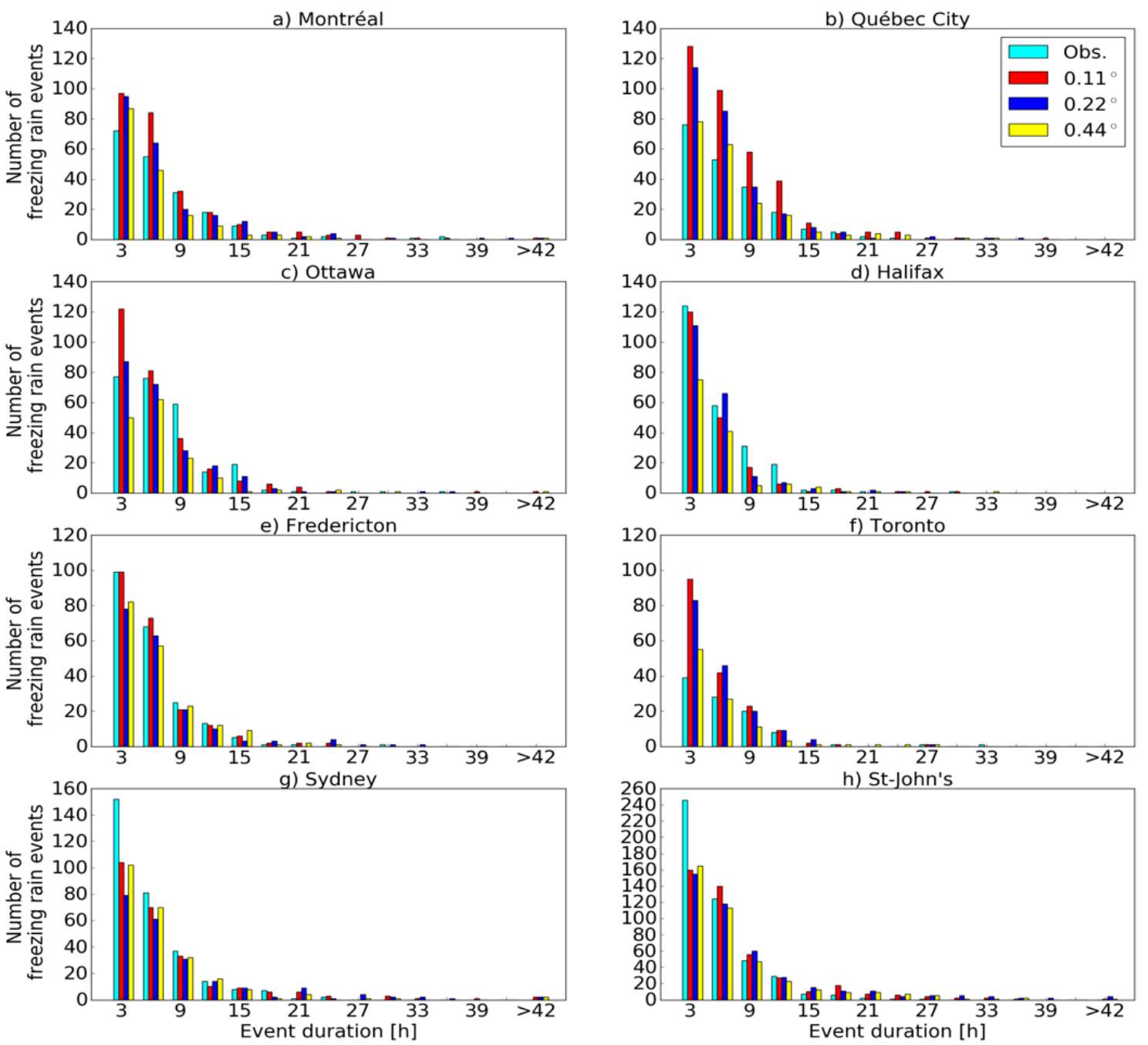

Fig. 11 Freezing rain event distributions for the 8 Canadian locations simulated at $0.11^{\circ}, 0.22^{\circ}$ and $0.44^{\circ}$ as well as observations for the period from 1980 to 2010. The location of these stations is given in Figure 2.

know that wind speed and direction in the St. Lawrence River Valley are better represented at higher resolution (Lucas-Picher et al., 2017). The presence of the low level easterly winds is favorable conditions to sustain the sub-freezing layer near the surface. As shown in Figure 13, the simulations are mainly colder than the observations for both types of events, with the exception of Ottawa SD, Toronto LD $\left(0.44^{\circ}\right)$ and Halifax SD $\left(0.11^{\circ}\right.$ and $\left.0.22^{\circ}\right)$. These cold temperatures at the surface could increase the bias of freezing rain occurrences by maintaining the relatively cold conditions near the surface. The mean surface temperature for LD (SD) events is -4.74 ($3.38),-4.26(-2.51)$ and $-3.54^{\circ} \mathrm{C}\left(-2.89^{\circ} \mathrm{C}\right)$ for the $0.11^{\circ}, 0.22^{\circ}$ and $0.44^{\circ}$ simulations, respectively 
and $-2.02^{\circ} \mathrm{C}\left(-1.80^{\circ} \mathrm{C}\right)$ for the observations. In Montréal, Québec City and Fredericton, all the simulations are colder but the $0.44^{\circ}$ simulation is comparable to observations. In Montréal, the poor definition of the wind channeling at this low resolution seems to be the cause degradation of the results as the mean surface temperature during these events is close $\left(\sim-0.22^{\circ} \mathrm{C}\right)$ to the observations. The strong overestimation of $\mathrm{LD}$ events at $0.11^{\circ}$ resolution for Québec City is, however, more difficult to explain. It may be a cause of the wetter bias at higher resolution or due to freezing rain events that are not always associated with local topography effects. As for the general underestimation in the Atlantic region, it may be attributed to the frequent freezing rain/drizzle formation through warm processes, which is not considered in Bourgouin (2000). This is particularly true in the St. John's, Newfoundland areas where strong temperature inversions in the low-level flow from the Labrador Sea are conducive to freezing drizzle formation (Strapp et al., 1996).

\section{4.b Captured single events}

It is reasonable to assume that freezing rain events produced would correlate with the observations because the simulations were driven by ERA-Interim reanalysis dataset. A better representation of observed freezing rain events in the St. Lawrence River Valley (Montréal and Québec City) was obtained at higher resolution (Table 1). For these two stations, the $0.11^{\circ}$ reproduced at least $12 \%$ more $\mathrm{LD}$ and $\mathrm{SD}$ events than the $0.44^{\circ}$. For example, more freezing rain events were reproduced at higher resolution at Québec City while there was a larger difference between the $0.44^{\circ}$ and $0.22^{\circ}$ than the $0.22^{\circ}$ and $0.11^{\circ}$ at Montréal. The simulation of LD and SD events at Toronto and the LD events at St. John's, with respect to the observations, is also slightly improved $(<11 \%)$ at higher resolutions. Finally, no significant difference was found at other stations. 

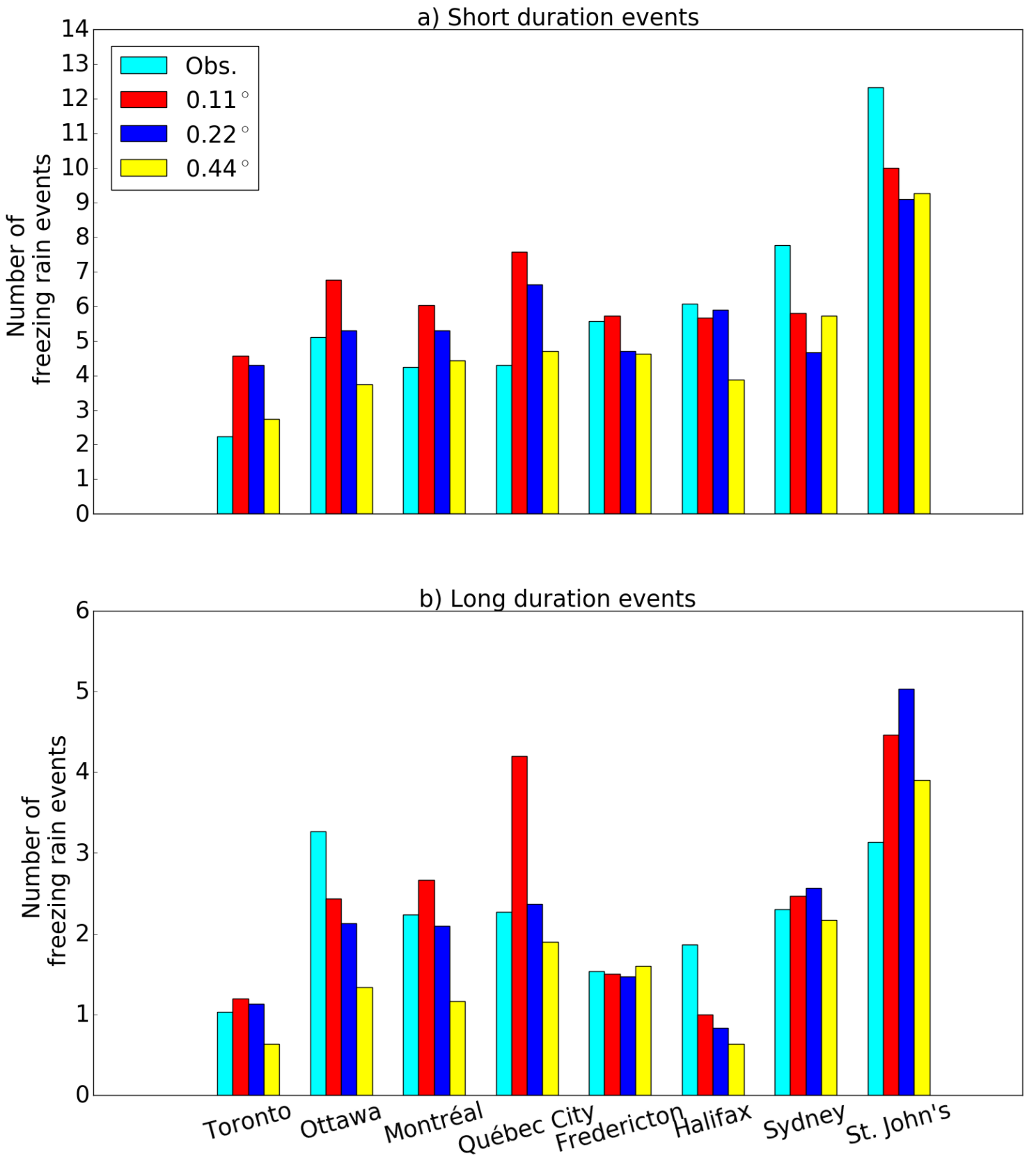

Fig. 12 Number of freezing rain events per year for the 8 stations simulated at $0.11^{\circ}, 0.22^{\circ}$ and $0.44^{\circ}$ as well as observations for the period from 1980 to 2010. (a) is the number of short and (b) is the number of long duration events. The location of these stations is given in Figure 2.

\section{4.c Observed events missed by the simulations}

The factors leading to the missed freezing rain events were investigated (Fig. 14). Recall that the method and the different cases are given in Figure 3 and 4. There is no clear difference between the resolutions for this analysis, however, at Montréal, the highest resolutions reproduced more 

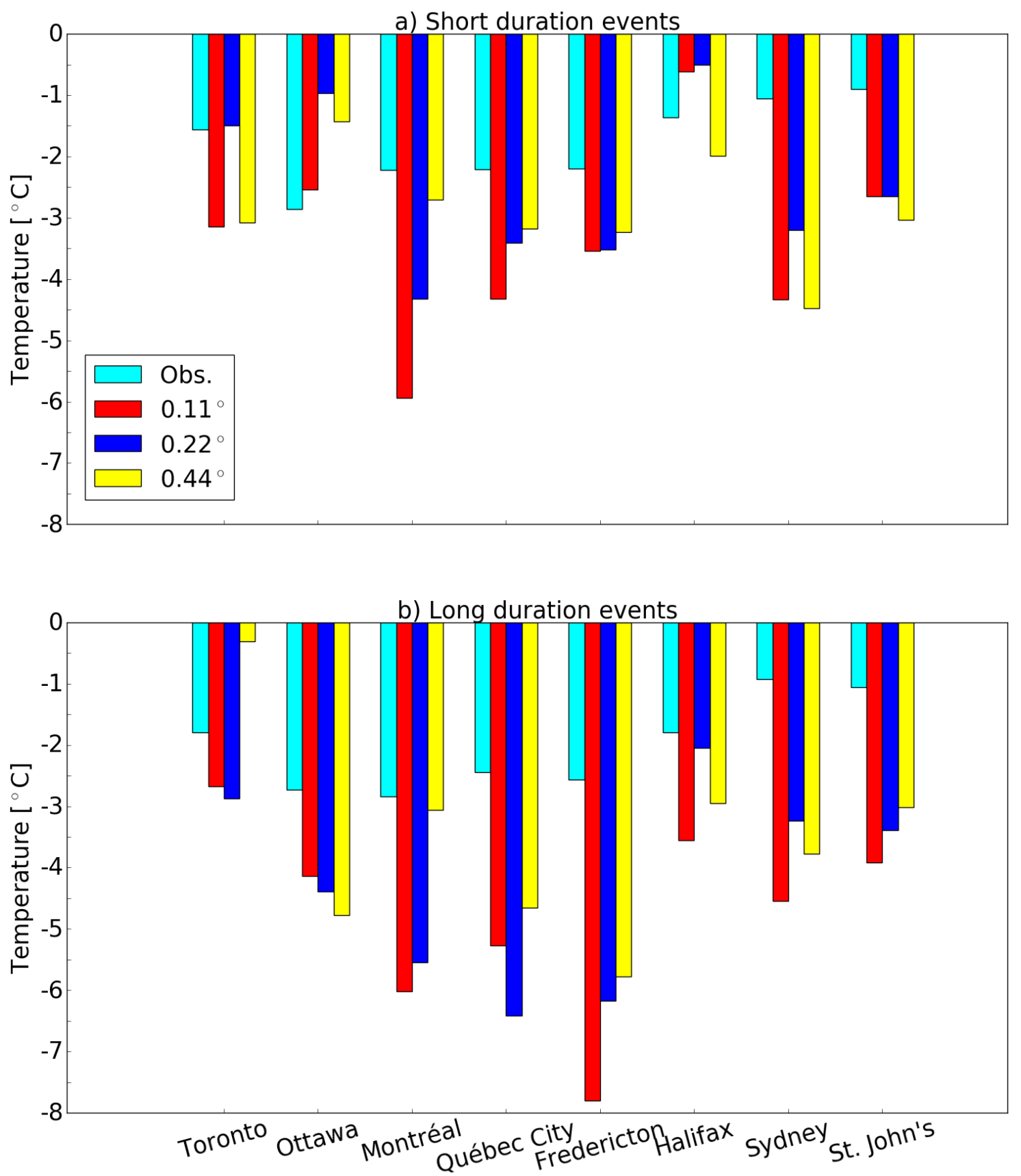

Fig. 13 Mean surface temperatures $\left({ }^{\circ} \mathrm{C}\right)$, when freezing rain occurs, simulated with the CRCM5 at $0.11^{\circ}, 0.22^{\circ}$, and $0.44^{\circ}$ horizontal resolutions and observed for 8 locations for the period from 1980 to 2010.

events (Table 1). There are some similarities and differences among stations. First, for all three stations (Montréal, Québec City and St. John's), freezing rain was mainly not produced because there was no precipitation at the surface (between 30-50\% at each location). Second, when precipitation reached the surface, no freezing rain was diagnosed because the melting layer was 
Table 1. Percentage of observed events reproduced by the simulations (\%). The results are obtained using the 1-point analysis. It includes for both short and long duration events (SD | LD). The last column is the mean percentage for all stations.

Resolution $\left(^{\circ}\right)$ Toronto Ottawa Montréal Québec City Fredericton Halifax Sydney St. John's \% of SD | LD

\begin{tabular}{llllllllll|r}
0.11 & $33 \mid 54$ & $47 \mid 69$ & $50 \mid 73$ & $59 \mid 82$ & $39 \mid 67$ & $37 \mid 59$ & $34 \mid 61$ & $44 \mid 71$ \\
0.22 & $39 \mid 58$ & $42 \mid 58$ & $47 \mid 73$ & $48 \mid 76$ & $37 \mid 72$ & $31 \mid 55$ & $31 \mid 65$ & $41 \mid 71$ & $72 \mid 28$ \\
0.44 & $28 \mid 48$ & $34 \mid 50$ & $34 \mid 61$ & $39 \mid 64$ & $40 \mid 70$ & $28 \mid 55$ & $38 \mid 64$ & $42 \mid 62$ \\
Obs. & & & & & & & $72 \mid 28$ \\
& & & & & &
\end{tabular}

near the surface and no refreezing layer was simulated (case 1) or because the melting layer was missing (case 2). Case 1 was the most simulated in Toronto (28 to $36 \%$ ) followed by case 2 ( 20\%). At Montréal and St. John's, both cases were equally simulated (20 to 25\%). Third, only a few occurrences $(<10 \%)$ show a melting layer aloft with warm surface temperature $\left(>0^{\circ} \mathrm{C}\right)$, which is the case 3 , or ice pellets instead of freezing rain (case 4). Therefore, the main reasons associated with missed freezing rain events when the model produced precipitation were because atmospheric conditions are too cold or too warm throughout the lower levels of the atmosphere. Indeed, the simulated surface temperature is mainly $>2^{\circ} \mathrm{C}$ for case 1 whereas temperatures were generally colder at the surface and aloft, between $-8^{\circ} \mathrm{C}$ and $-2^{\circ} \mathrm{C}$, for case 2 (St-Pierre, 2018).

\section{4.d Specific case study}

Examples of specific cases were studied to assess the impact of the model resolutions on freezing rain occurrences. The 1998 Ice Storm is presented because detailed observations are available (Bresson et al., 2017). This Ice Storm occurred in two phases (Henson, Stewart, Kochtubajda, \& Thériault, 2011). The first phase of the storm was well reproduced by every simulation according to the observations (Fig. 15a,c and e). All resolutions simulated freezing rain, ice pellets and snow at the beginning of the storm. During the second phase, the $0.11^{\circ}$ and $0.22^{\circ}$ resolutions are more comparable to observations. The $0.44^{\circ}$ resolution produced surface temperatures $>0^{\circ} \mathrm{C}$ during that phase (Fig. 15b), which led to rain instead of freezing rain 

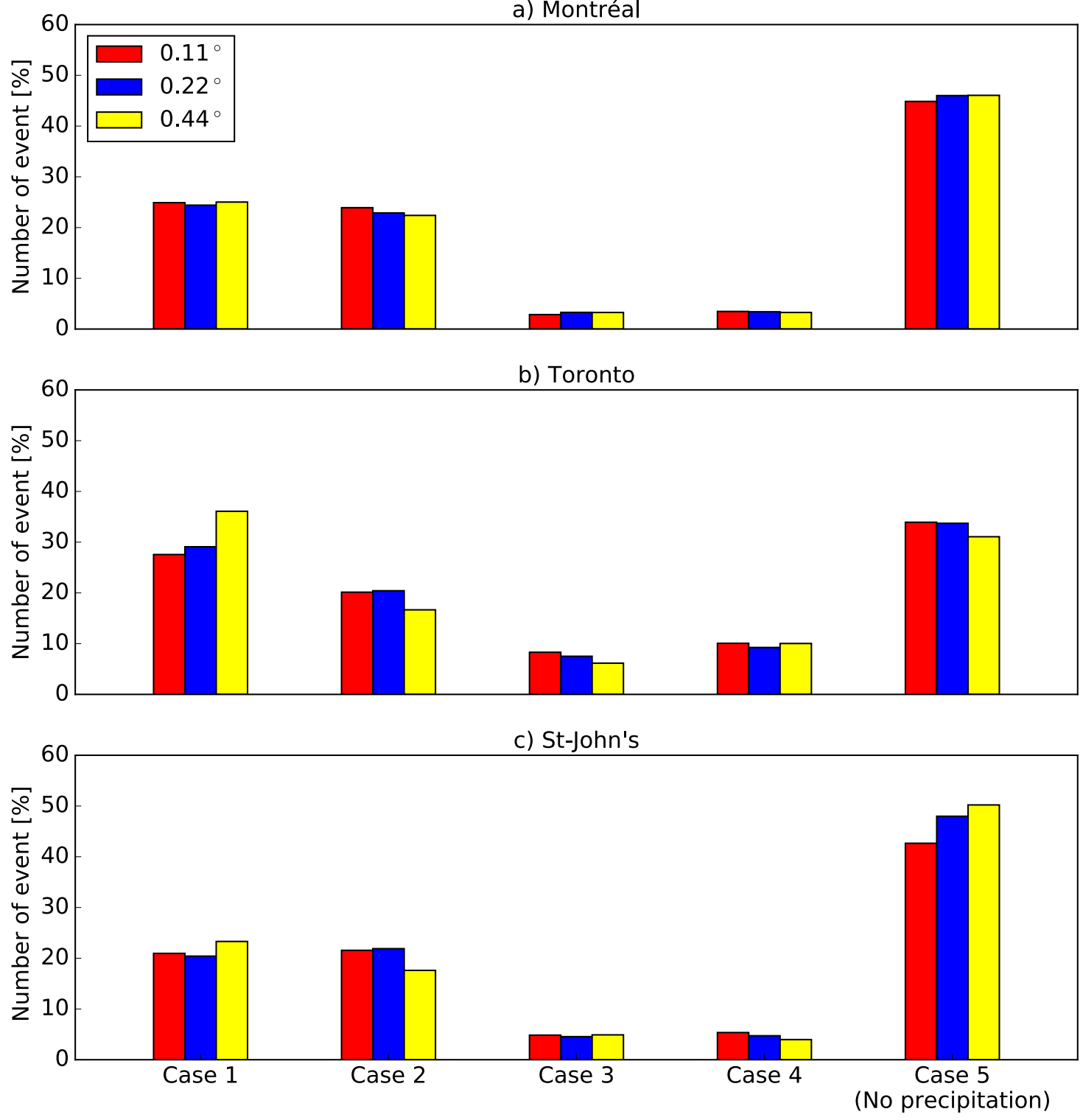

Fig. 14 Percentage of the occurrences of each case during events not reproduced within the $12 \mathrm{~h}$ before and after the observed freezing rain events. Each case is referred to in Figure 4. Case 5 represents occurrences without precipitation.

Observations also suggested that ice pellets reached the surface during the second phase, which was not reproduced by all the simulations. This could be explained because the model simulated warmer temperatures $\left(>5^{\circ} \mathrm{C}\right)$ aloft. The modelled temperatures were too warm leading to complete melting of ice particles, which produced supercooled drops that froze upon impact with the surface.

The spatial distribution of the accumulated amount of freezing rain during the storm has 

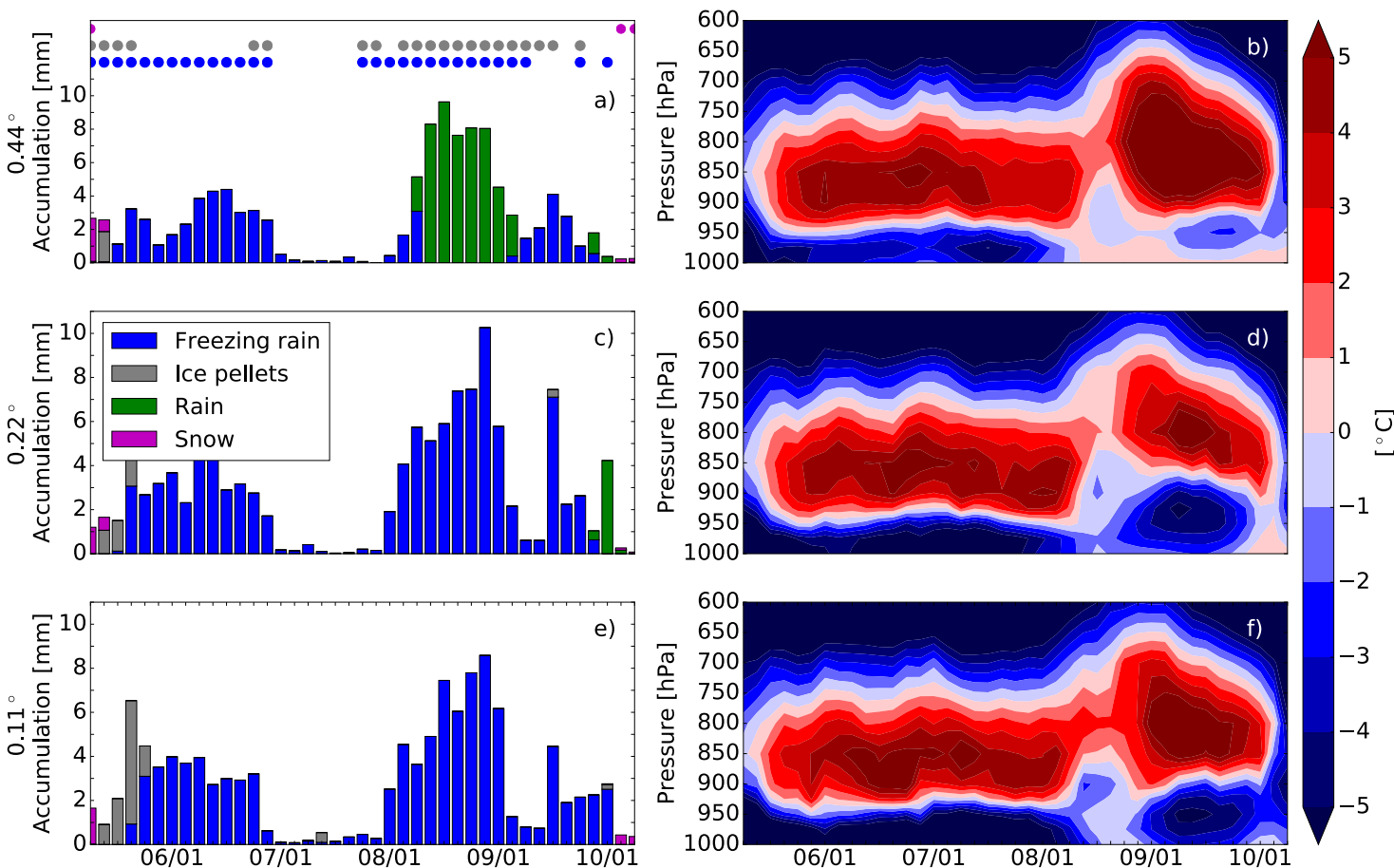

Fig. 15 Time evolution of the precipitation types at the surface during the January 1998 Ice Storm simulated by CRCM5 at (a) $0.44^{\circ}$, (c) $0.22^{\circ}$ and (e) $0.11^{\circ}$ horizontal resolutions for the nearest points from Montréal (YUL). The bars are the total amount of precipitation, which indicates the amount of each precipitation type, during the simulated event. Observed precipitation types are also included in (a) as colored dots. The time evolution of the vertical temperature profiles simulated by CRCM5, for the same period, is shown for the (b) $0.44^{\circ}$ (d) $0.22^{\circ}$ and (f) $0.11^{\circ}$ simulations.

been investigated (Fig. 16). The maximum amount has been reproduced farther west by the $0.11^{\circ}$ (Bresson et al., 2017) and $0.22^{\circ}$ resolutions and even farther northwest in the $0.44^{\circ}$ simulation, which explains the occurrence of rain in the second phase of the storm. All simulations reproduced the precipitation types and amounts well, even if all resolutions simulated the maximum of intensity farther west. The $0.11^{\circ}$ and $0.22^{\circ}$ resolutions, however, better reproduced the location and the key features such as the spatial distribution with respect to topography and observations.

\section{Conclusions}

This study aimed to assess the added value of the higher horizontal resolution to simulate atmospheric conditions leading to freezing rain. To achieve this goal, three CRCM5 simulations at horizontal resolutions of $0.11^{\circ}, 0.22^{\circ}$ and $0.44^{\circ}$ driven by ERA-Interim were analysed, using 
a) $0.44^{\circ}$

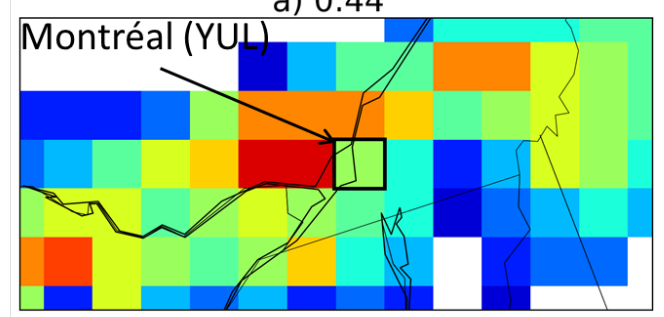

c) $0.11^{\circ}$

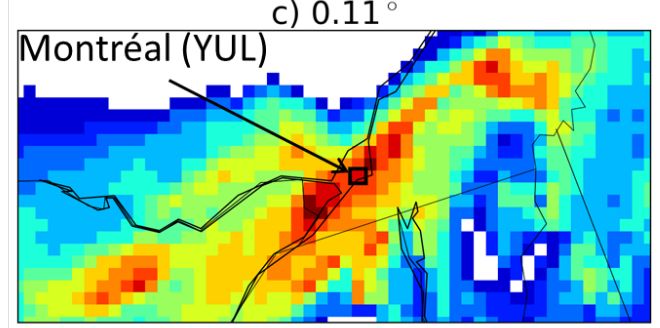

b) $0.22^{\circ}$

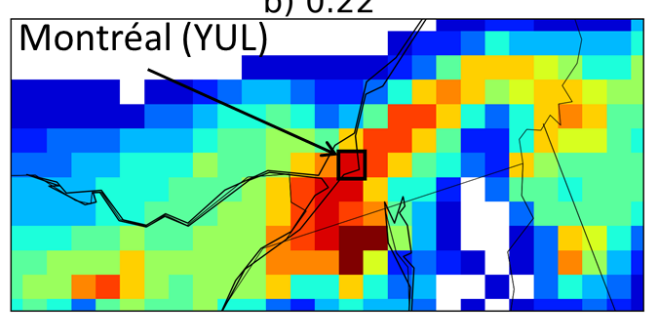

d) Observations

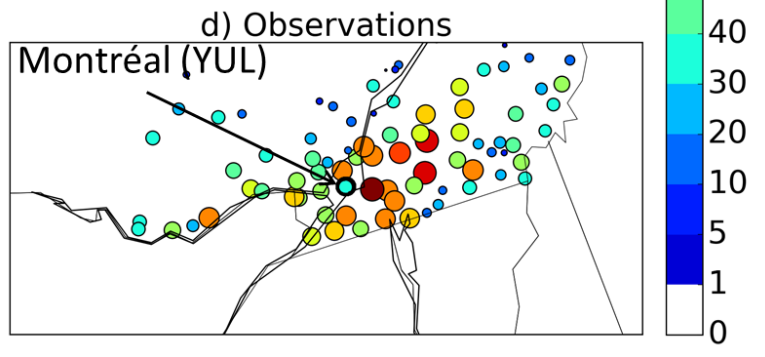

120

110

100

90

80

70

60

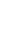

。

0 है

Fig. 16 Total accumulated freezing rain during the January 1998 Ice storm and its distribution over southern Québec and, for the simulations, northeastern United States. The grid cell including the Montréal airport (YUL) is indicated by the black square and circle, for the model and the observations, respectively.

the precipitation-typing algorithm of Bourgouin (2000). A basic climatology study and an eventbased analysis of freezing rain were performed. The key conclusions are as follows.

- The climatology based on 31 years of simulations is evaluated with respect to observations of freezing rain (MANOBS). The large-scale patterns of freezing rain distributions are well simulated at all resolutions.

- The pattern of seasonal variability of freezing rain occurrences is similar at all resolutions. The higher resolution simulations $\left(0.11^{\circ}\right.$ and $\left.0.22^{\circ}\right)$ tend to overestimate freezing rain with respect to the lower resolution simulation. The simulated seasonal variability, however, varies for the 8 locations studied.

- The climatology showed an overestimation of the number of freezing rain hours per year at higher resolution. However, the monthly analysis over specific locations and the targeted analysis over the St. Lawrence River Valley show that the coarser resolution $\left(0.44^{\circ}\right)$ generally underestimates the occurrences of freezing rain events.

- Special attention was paid to the St. Lawrence River Valley where the topography is known to 
be important, and the representation of freezing rain events is hence expected to be improved by higher horizontal model resolution. Our analyses show that freezing rain is reproduced well during spring, but it is overestimated during winter and fall. There is an increase in simulated freezing rain occurrences with increasing horizontal resolution. This could be due to a better representation of the wind channeling effects leading to a sub-freezing layer near the surface. However, the occurrence is overestimated in these simulations, which could be due to colder surface temperatures during freezing rain events that help sustained the sub-freezing layer near the surface. The general wet bias may also partly contribute to the higher occurrence of precipitation during favorable atmospheric conditions for freezing rain.

- The event-based analysis at the 8 locations suggest that the $0.11^{\circ}$ and $0.22^{\circ}$ simulations are able to better reproduce freezing rain events. In contrast, the $0.44^{\circ}$ simulation underestimate freezing rain at most locations, for both long and short duration events. For example, the $0.11^{\circ}$ simulation reproduced well the SD events at Fredericton and Halifax and overestimated the LD events at Montréal, Toronto, and Québec City as well as the SD event at Ottawa whereas they are all underestimated by the $0.44^{\circ}$ resolution. Despite these underestimations, at Québec City the $0.44^{\circ}$ simulation shows clear improvement over the $0.11^{\circ}$ and over the $0.22^{\circ}$ for the simulation of SD events. The freezing rain events that were not simulated by the models, where mostly missed due to the absence of precipitation $\left(<1 \mathrm{~mm} \mathrm{~d}^{-1}\right)$ in the simulations. In case precipitation occurred, but the freezing rain events were still not reproduced by the models, this was mostly due to an absence of simulated cold air near the surface (case 1) or the absence of a simulated melting layer aloft (case 2).

- An extreme event, the 1998 Ice Storm, was chosen to illustrate the time evolution of different precipitation types at the surface. This storm impacted the 31-year climatology by 10 to $30 \%$ for stations located in the St. Lawrence River Valley. The higher resolution simulations reproduced the precipitation type evolution at Montréal well, but only rain was diagnosed at $0.44^{\circ}$ horizontal resolution. The storm in the low resolution model was simulated farther northwest, compared to the observations. This could be due to a poor representation of the St. 
Lawrence River Valley topography in the $0.44^{\circ}$ simulation, leading to a poor representation of the wind channeling effect near the surface.

There are some limitations to this study. First, the available observations are mainly occurrence of different precipitation types. It would be useful to also use accumulations to investigate the added value of the model resolution on the intensity of freezing precipitation. Furthermore, the distinction of the different precipitation types in such complex weather conditions is a difficult task, and while the observations are a combination of automatic measurements and human observers, we expect a measuring error in the reported data. Second, 3-hourly model output limits the study of the short duration events and hence leads to an overestimation of the occurrence of freezing rain events, since most of the freezing rain events last less then 3 hours. Hourly model outputs would allow a better representation of the occurrence of short duration freezing rain events. To compare with observations, heated precipitation gauge information would be needed. Third, freezing rain formed through warm rain process is not included in Bourgouin, (2000). To take this process into account, one would need to diagnose the conditions in which supercooled precipitation reach the surface without being produced by melting of solid precipitation. Fourth, it would be interesting to investigate the influence of the model vertical resolution as well, as it may impact the vertical temperature structure favorable for freezing rain and ice pellets. Finally, it is recognized that the event-based study using the 1-point analysis has some limitations. Here the model is forced only with prognostic variables (wind component, temperature, pressure and humidity) at the boundary by the ERA-Interim reanalysis. In addition, the analysis depends on the chosen grid point, which in turn impacts the timing and location of the studied events.

Overall, we find improvements as well as deteriorations for the simulation of freezing rain in the higher resolution simulations compared to the coarse resolution simulation, which is in agreement with previous findings (Xue, Janjic, Dudhia, Vasic, \& De Sales, 2014; Di Luca, Argüeso, Evans, de Elía, \& Laprise, 2016; Luca-Picher et al., 2017). Large-scale patterns of freezing rain are similar at all resolutions. On the other hand, for most locations, the distribution of freezing rain events as well as the detail occurrences of local precipitation is better represented in simula- 
tions with higher horizontal resolutions $\left(0.11^{\circ}\right.$ and $\left.0.22^{\circ}\right)$. Further research should be conducted to investigate the benefit of using higher resolution for freezing rain.

\section{Acknowledgment}

The authors would like to thank the funding agencies, Canadian Network for Regional Climate and Weather Processes (CNRCWP) and NSERC Discovery grant. One of the authors (MSP) would like to thank the faculty of sciences at UQÀM for the scholarship. The CRCM5 data has been generated and supplied by Ouranos. The CRCM5 was developed at UQÀM in collaboration with ECCC. The CRCM5 computations were made on the supercomputer guillimin from McGill University, managed by Calcul Québec and Compute Canada. The operation of the supercomputer is funded by the Canada Foundation for Innovation (CFI), le ministère de l'Économie, de la Science et de l'innovation du Québec (MESI) and le Fonds de recherche du Québec - Nature et technologies (FRQNT) 


\section{References}

American Meteorological Society, cited 2018: Freezing drizzle. Glossary of Meteorology.

[Available online at http://glossary.ametsoc.org/wiki/Freezing_drizzle].

Arakawa, A., \& Lamb, V. R. (1977). Computational design of the basic dynamical processes of the UCLA general circulation model. General circulation models of the atmosphere, 17, 173-265.

Armenakis, C., \& Nirupama, N. (2014). Urban impacts of ice storms: Toronto December 2013. Natural hazards, 74(2), 1291-1298.

Bélair, S., Mailhot, J., Girard, C., \& Vaillancourt, P. (2005). Boundary layer and shallow cumulus clouds in a medium-range forecast of a large-scale weather system. Monthly weather review, 133(7), 1938-1960.

Benjamin, S. G., Brown, J. M., \& Smirnova, T. G. (2016). Explicit precipitation-type diagnosis from a model using a mixed-phase bulk cloud-precipitation microphysics parameterization. Weather and Forecasting, 31(2), 609-619.

Benoit, R., Côté, J., \& Mailhot, J. (1989). Inclusion of a TKE boundary layer parameterization in the Canadian regional finite-element model. Monthly weather review, 117(8), 17261750 .

Bourgouin, P. (2000). A method to determine precipitation types. Weather and Forecasting, 15(5), 583-592.

Bresson, É., Laprise, R., Paquin, D., Thériault, J. M., \& de Elía, R. (2017). Evaluating the ability of CRCM5 to simulate mixed precipitation. Atmosphere-Ocean, 55(2), 79-93.

Carrière, J. M., Lainard, C., Le Bot, C., \& Robart, F. (2000). A climatological study of surface freezing precipitation in Europe. Meteorological Applications, 7(3), 229-238.

Cheng, C. S., Auld, H., Li, G., Klaassen, J., \& Li, Q. (2007). Possible impacts of climate change on freezing rain in south-central Canada using downscaled future climate scenarios. Natural Hazards and Earth System Science, 7(1), 71-87.

Cholette, M., Laprise, R., \& Thériault, J. M. (2015). Perspectives for very high-resolution climate simulations with nested models: illustration of potential in simulating St. Lawrence River Valley channelling winds with the fifth-generation Canadian regional climate model. Climate, 3(2), 283-307.

Cortinas Jr, J. V., Bernstein, B. C., Robbins, C. C., \& Strapp, J. W. (2004). An analysis of freezing rain, freezing drizzle, and ice pellets across the United States and Canada: 1976-90. Weather and Forecasting, 19(2), 377-390. 
Côté, J., Desmarais, J. G., Gravel, S., Méthot, A., Patoine, A., Roch, M., \& Staniforth, A. (1998). The operational CMC-MRB global environmental multiscale (GEM) model. Part II: Results. Monthly Weather Review, 126(6), 1397-1418.

Davies, H. (1976). A lateral boundary formulation for multi-level prediction models. Quarterly Journal of the Royal Meteorological Society, 102(432), 405-418.

Dee, D. P., Uppala, S. M., Simmons, A. J., Berrisford, P., Poli, P., Kobayashi, S., ... \& Bechtold, P. (2011). The ERA-Interim reanalysis: Configuration and performance of the data assimilation system. Quarterly Journal of the royal meteorological society, 137(656), 553-597.

Delage, Y. (1997). Parameterising sub-grid scale vertical transport in atmospheric models under statically stable conditions. Boundary-Layer Meteorology, 82(1), 23-48.

Delage, Y., \& Girard, C. (1992). Stability functions correct at the free convection limit and consistent for both the surface and Ekman layers. Boundary-Layer Meteorology, 58(12), 19-31.

Di Luca, A., Argüeso, D., Evans, J. P., de Elía, R., \& Laprise, R. (2016). Quantifying the overall added value of dynamical downscaling and the contribution from different spatial scales. Journal of Geophysical Research: Atmospheres, 121(4), 1575-1590.

Dore, M. H. (2003). Forecasting the conditional probabilities of natural disasters in Canada as a guide for disaster preparedness. Natural Hazards, 28(2-3), 249-269.

Groisman, P. Y., Bulygina, O. N., Yin, X., Vose, R. S., Gulev, S. K., Hanssen-Bauer, I., \& Førland, E. (2016). Recent changes in the frequency of freezing precipitation in North America and Northern Eurasia. Environmental Research Letters, 11(4), 045007.

Harris, I., Jones, P. D., Osborn, T. J., \& Lister, D. H. (2014). Updated high-resolution grids of monthly climatic observations-the CRU TS3. 10 Dataset. International journal of climatology, 34(3), 623-642.

Henson, W., Stewart, R., Kochtubajda, B., \& Thériault, J. (2011). The 1998 Ice Storm: Local flow fields and linkages to precipitation. Atmospheric research, 101(4), 852-862.

Kain, J. S., \& Fritsch, J. M. (1990). A one-dimensional entraining/detraining plume model and its application in convective parameterization. Journal of the Atmospheric Sciences, 47(23), 2784-2802.

Kajikawa, M., Sakurai, K. I., \& Kikuchi, K. (1988). Characteristic features of supercooled raindrops in the mid-winter season of Arctic Canada. Journal of the Meteorological Society of Japan. Ser. II, 66(2), 393-398.

Kochtubajda, B., Mooney, C., \& Stewart, R. (2017). Characteristics, atmospheric drivers and occurrence patterns of freezing precipitation and ice pellets over the Prairie Provinces and Arctic Territories of Canada: 1964-2005. Atmospheric Research, 191, 115-127. 
Kuo, H. L. (1965). On formation and intensification of tropical cyclones through latent heat release by cumulus convection. Journal of the Atmospheric Sciences, 22(1), 40-63.

Lambert, S. J., \& Hansen, B. K. (2011). Simulated changes in the freezing rain climatology of North America under global warming using a coupled climate model. Atmosphereocean, 49(3), 289-295.

Laprise, R. (1992). The Euler equations of motion with hydrostatic pressure as an independent variable. Monthly weather review, 120(1), 197-207.

Lecomte, E. L., Pang, A. W., \& Russell, J. W. (1998). Ice storm'98 (p. 39). Ottawa, Canada: Institute for Catastrophic Loss Reduction.

Li, J., \& Barker, H. W. (2005). A radiation algorithm with correlated-k distribution. Part I: Local thermal equilibrium. Journal of the atmospheric sciences, 62(2), 286-309.

Liu, C., Ikeda, K., Rasmussen, R., Barlage, M., Newman, A. J., Prein, A. F., ... \& Dudhia, J. (2017). Continental-scale convection-permitting modeling of the current and future climate of North America. Climate Dynamics, 49(1-2), 71-95.

Lucas-Picher, P., Laprise, R., \& Winger, K. (2017). Evidence of added value in North American regional climate model hindcast simulations using ever-increasing horizontal resolutions. Climate Dynamics, 48(7-8), 2611-2633.

Martynov, A., Laprise, R., Sushama, L., Winger, K., Šeparović, L., \& Dugas, B. (2013). Reanalysis-driven climate simulation over CORDEX North America domain using the Canadian Regional Climate Model, version 5: model performance evaluation. Climate dynamics, 41(11-12), 2973-3005.

Matte, D., Thériault, J. M., \& Laprise, R. (2018). Mixed precipitation occurrences over southern Québec, Canada, under warmer climate conditions using a regional climate model. Climate Dynamics, 1-17.

McFarlane, N. A. (1987). The effect of orographically excited gravity wave drag on the general circulation of the lower stratosphere and troposphere. Journal of the atmospheric sciences, 44(14), 1775-1800.

Mearns, L. O., Gutowski, W., Jones, R., Leung, R., McGinnis, S., Nunes, A., \& Qian, Y. (2009). A regional climate change assessment program for North America. Eos, Transactions American Geophysical Union, 90(36), 311-311.

Meyers, M. P., DeMott, P. J., \& Cotton, W. R. (1992). New primary ice-nucleation parameterizations in an explicit cloud model. Journal of Applied Meteorology, 31(7), 708-721.

Milton, J., \& Bourque, A. (1999). A Climatological Account of the January 1998 Ice Storm in Quebec: Scientific Report. Environment Canada, Atmospheric Sciences and Climate Monitoring Division. 
Mironov, D., Heise, E., Kourzeneva, E., Ritter, B., Schneider, N., \& Terzhevik, A. (2010). Implementation of the lake parameterisation scheme FLake into the numerical weather prediction model COSMO.

Ressler, G. M., Milrad, S. M., Atallah, E. H., \& Gyakum, J. R. (2012). Synoptic-scale analysis of freezing rain events in Montreal, Quebec, Canada. Weather and Forecasting, 27(2), $362-378$

Roberts, E., \& Stewart, R. E. (2008). On the occurrence of freezing rain and ice pellets over the eastern Canadian Arctic. Atmospheric Research, 89(1-2), 93-109.

Schär, C., Frei, C., Lüthi, D., \& Davies, H. C. (1996). Surrogate climate-change scenarios for regional climate models. Geophysical Research Letters, 23(6), 669-672.

Šeparović, L., Alexandru, A., Laprise, R., Martynov, A., Sushama, L., Winger, K., ... \& Valin, M. (2013). Present climate and climate change over North America as simulated by the fifth-generation Canadian regional climate model. Climate Dynamics, 41(11-12), 31673201.

Stewart, R. E., Thériault, J. M., \& Henson, W. (2015). On the characteristics of and processes producing winter precipitation types near 0 C. Bulletin of the American Meteorological Society, 96(4), 623-639.

St-Pierre, M. (2018). Évaluation de la valeur ajoutée associée à une augmentation de la résolution horizontale du modèle régional canadien du climat version 5 pour la production de précipitations verglaçantes (Unpublished master's thesis). Université du Québec à Montréal, Montréal.

Strapp, J. W., Stuart, R. A., \& Isaac, G. A. (1996). A Canadian climatology of freezing precipitation, and a detailed study using data from St. John's, Newfoundland. In Proc. Int. Conf. on Aircraft Inflight Icing (Vol. 2, pp. 45-56). Springfield, Va: Fed. Aviat. Admin.

Sundqvist, H., Berge, E., \& Kristjánsson, J. E. (1989). Condensation and cloud parameterization studies with a mesoscale numerical weather prediction model. Monthly Weather Review, 117(8), 1641-1657.

Thériault, J. M., Stewart, R. E., Milbrandt, J. A., \& Yau, M. K. (2006). On the simulation of winter precipitation types. Journal of Geophysical Research: Atmospheres, 111(D18).

Verseghy, D. (2009). CLASS-The Canadian Land Surface Scheme (Version 3.4) Technical Documentation (Version 1.1), Environment Canada. Climate Research Division, Science and Technology Branch, Downsview, Ontario, Canada.

Verseghy, D. (1991). CLASS-A Canadian land surface scheme for GCMs. I. Soil model. International Journal of Climatology, 11(2), 111-133. 
Xue, Y., Janjic, Z., Dudhia, J., Vasic, R., \& De Sales, F. (2014). A review on regional dynamical downscaling in intraseasonal to seasonal simulation/prediction and major factors that affect downscaling ability. Atmospheric research, 147, 68-85.

Zadra, A., McTaggart-Cowan, R., \& Roch, M. (2012). Recent changes to the orographic blocking. Seminar presentation, RPN, Dorval, Canada, 30 March 2012.

Zadra, A., Roch, M., Laroche, S., \& Charron, M. (2003). The subgrid-scale orographic blocking parametrization of the GEM Model. Atmosphere-ocean, 41(2), 155-170. 